Research Article

\title{
Solid-Gas Flow Characteristics of Drilling Bit-Rod Integral Structure
}

\author{
Hongtu Zhang, ${ }^{1,2,3}$ Ouya Zhang, ${ }^{1}$ Le Wei, ${ }^{4}$ and Banghua Yao $\mathbb{i D}^{2,3}$ \\ ${ }^{1}$ School of Safety Science and Engineering, Henan Polytechnic University, Jiaozuo, Henan 454003, China \\ ${ }^{2}$ State Key Laboratory Cultivation Base for Gas Geology and Gas Control, Henan Polytechnic University, Jiaozuo, \\ Henan 454003, China \\ ${ }^{3}$ State Collaborative Innovation Center of Coal Work Safety and Clean-Efficiency Utilization, Jiaozuo 454003, China \\ ${ }^{4}$ China Coal Technology and Engineering Group Chongqing Research Institute, Chongqing 400037, China
}

Correspondence should be addressed to Banghua Yao; yaobanghua@126.com

Received 25 June 2020; Revised 25 August 2020; Accepted 1 September 2020; Published 24 September 2020

Academic Editor: Zhiqiang Yin

Copyright (C) 2020 Hongtu Zhang et al. This is an open access article distributed under the Creative Commons Attribution License, which permits unrestricted use, distribution, and reproduction in any medium, provided the original work is properly cited.

Sampling based on negative pressure pneumatic conveying method is an important theory in determining coal bed methane (CBM) content. The coal-gas two-phase flow path is an integrated structure composed of polycrystalline diamond compact (PDC) bit and drilling rod. In this work, CFD-DEM coupling numerical simulation was adopted to study the solid-gas flow characteristics of an integrated structure having PDC bit and gas velocity pipe under different gas velocity and solid mass flow rates. The results showed that the gas phase had a reverse velocity zone at the PDC bit. The reverse velocity zone gradually decreased with increase of gas velocity. In addition, a high-velocity band in drill pipe became apparent for the particle phase; there was an obvious bottom flow characteristic at the PDC bit and an area of the highest layer thickness in the drill pipe. Under the same gas velocity, the location of the area of the highest layer thickness shifted from the drill bit with the increase of solid mass flow rate. Increase in the gas velocity resulted in a rapid increase of the velocity of coal particles, while the bottom flow characteristics of coal particles weakened and the suspension flow gradually appeared. The results of this study are of great significance for optimizing the gas velocity based on negative pressure pneumatic conveying technique.

\section{Introduction}

Pneumatic conveying is a common method for transportation of bulk material over long distance in industries such as petrol, agriculture, mining, and chemical due to its efficiency, adaptability, and operability. A typical pneumatic conveying consists of feeder equipment, pipelines, and power device. Gas velocity, solid-gas ratio, pressure drop, and flow pattern are the main factors for evaluating the pneumatic conveying system. The solid-gas flow characteristics of pneumatic conveying under different operating parameters are key factor for optimizing the system.

Although experiments can effectively investigate the flow pattern, pressure drop, and particle concentration of pneumatic conveying under different operating parameters, it is difficult to determine the optimal parameters for complex and uneconomical solid-gas flow.
The development of CFD (computational fluid dynamics) has proved to be a useful alternative method for investigating pneumatic conveying. Many works on pneumatic conveying have been carried out using CFD-DPM. Huber et al. [1] calculated the dispersed gas-solid flows in pipe systems using CFD-DPM which included all important effects, such as turbulence, two-way coupling, particle transverse lift forces, and particle-wall collisions including wall roughness and interparticle collisions. Lain et al. [2] investigated the different flow characteristics of channel and pipe flow under different effects, such as wall roughness and the degree of coupling (i.e., two- or four-way) via Euler-Lagrange. Sommerfeld et al. [3] studied the parameters influencing dilute phase pneumatic conveying through pipe systems.

The DPM neglects the particle-particle interaction [4], because it more suited for the study of dilute phase flow [5]. 
When researchers need more information about the particle behavior, for example, the particle degradation during pneumatic conveying, particle-particle interaction should not be neglected. To obtain more particle information, Tsuji et al. [6] proposed a new CFD-DEM method (computational fluid dynamics-discrete element method), which has been widely used in petrol, agriculture, mining, and chemical industries. Akhshik et al. [7, 8] investigated the drilling cuttings flow characteristics in petrol industry under different pipeline rotations by the CFD-DEM coupling method. In agriculture industry, Li et al. [9] studied the grain motion in the air-and-screen cleaning device of combining harvester by the CFD-DEM method. Dai et al. [10] investigated the motion simulation and tested threshed grains in tapered threshing and transmission device for plot wheat breeding based on CFD-DEM. In chemical industry, Kruggel-Emden et al. [11] studied the rope formation and dispersion of nonspherical particles during pneumatic conveying in a pipe bend by the CFD-DEM. Kumar [12] studied the pressure drop in the bend. Korevaar et al. [13] revealed the particle charging mechanism during the pneumatic conveying. The CFD-DEM method was also used to study the physical mechanisms involved in slug transport and pipe blockage during horizontal pneumatic conveying [14].

In the mining industry, Shao et al. [15] studied the flow characteristics of drilling cuttings during coal bed methane extraction drilling while Zhou et al. [16] revealed the distribution law of fine sealing material particles in the narrow channels of coal seam during the secondary sealing process of gas drainage drilling.

However, it is noteworthy that previous works on the flow characteristics of pneumatic conveying paid more attention to the characteristics of the solid-gas flow into the rod, while there is insufficient study about the physical structure effect of the solid-gas flow into the rod.

The prerequisite for efficient CBM extraction is determination of its precise gas content. A typical application of pneumatic conveying is the sampling method based on negative pressure pneumatic conveying for determining the content of coal bed methane in underground coal mines. Before the coal sample is collected, the gas-coal flowed into the bit-drilling rod structure by the bit firstly and then to the drilling rod during the sampling process. And the gas-coal flow in the bit-drilling rod structure affected the sampling process. Therefore, studying the gas-coal flow characteristics inside the structure composed of bit-drill rod had an important guiding for optimizing the design of sampling drilling bit-drill rod structure.

In this work, the integrated structure of the coal-gas flow path during the drilling bit-rod was constructed. The CFDDEM numerical simulation method was then applied to study the coal-gas flow characteristics under different operating parameters.

\section{Geometry and Mesh}

The bit is based on a common PDC three-wing bit and there are three fluid holes, which are evenly distributed on the circumference. Simplifying the PDC bit structure with fluid holes, the inclination angle is $30^{\circ}$ and the center diameter is $0.02 \mathrm{~m}$. The total effective fluid holes cross-sectional area formed is equal to the cross-sectional area of the circular surface of rod with diameter of $0.04 \mathrm{~m}$. In this study, the total geometric structure length was $5 \mathrm{~m}$ with an improved PDC drill bit and a section of drill rod with inner diameter of $0.04 \mathrm{~m}$. And the improved PDC bit had three fluid holes with inclination angle of 30 degrees each and a total effective cross section area equaled that of the drill rod, the actual diagram of the bit, and the drill rod as shown in Figure 1. The drilling rod has a diameter of $40 \mathrm{~mm}$, leading to an integrated structure which constitutes the bit-drilling rod $(0-5 \mathrm{~m})$ model. Gambit 2.4.6 preprocessing software was used to model and mesh the grid into blocks: the grid part of the drill bit adopts Trid type, Tet/hybrid unit, interval size $=0.005$; the connecting part of the drill pipe is of Copper type, Hex/ Wedge unit, interval size $=0.02$, as shown in Figure 1 (the part of the drill pipe is a partial schematic diagram). For verification, the mesh independent of the calculation was 16384,34610 , and 66542, respectively. The pressure drop and the difference between the calculated results at the same gas velocity are shown in Table 1.

\section{CFD-DEM Coupling Simulation}

3.1. CFD-DEM Coupling Simulation Process. In this work, two commonly used numerical software applications FLUENT and EDEM were selected as the CFD and DEM operation platforms, respectively. The CFD-DEM simulation procedure is as follows: the particle phase is added after the gas phase flow field reaches a steady state. The gas phase calculates convergence within a single time step; the particles then update the motion state according to the gas phase data in the grid unit. In the new time step, the gas phase flow information is updated according to the state of particle motion in the grid cell and reaches the convergence state. Back and forth cycling continues until a steady state is reached; the calculation procedure is as shown in Figure 2.

FLUENT-EDEM coupling algorithm has two coupling methods, namely, Lagrange and Euler. Compared with the Euler-Lagrangian method, the Euler-Euler coupling method fully considers the force between the particle-fluid phase, particle-particle, and particle-wall surface. Besides, EulerEuler coupling can be used in both dilute phase and dense phases. Therefore, the Euler-Euler coupling method was used in the current study.

3.2. Solid Phase Governing Equation. Newton's second kinetic equation was adopted to describe the particle motion, and the coal particle $i$ motion equation is as follows:

Particle $i$ motion can be described by the following equation:

$$
\begin{aligned}
& F_{I}=m_{i} \ddot{v}_{i}, \\
& M_{i}=I_{i} \ddot{\theta}_{i},
\end{aligned}
$$




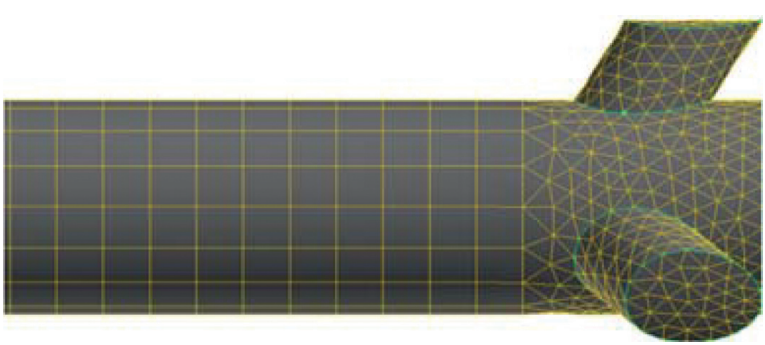

(a)

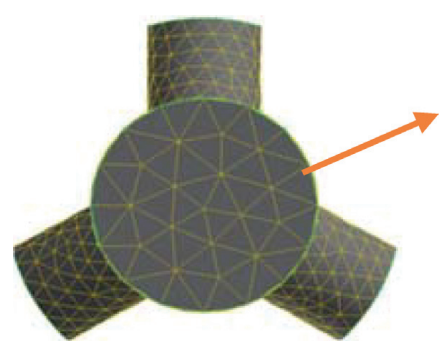

(b)

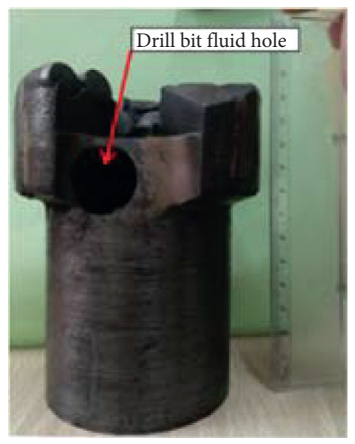

(c)

FIgURE 1: The meshing of drilling bit meshing.

TABLE 1: The details for the grid independence study.

\begin{tabular}{lcc}
\hline Mesh number & Pressure $(\mathrm{Pa})$ & Error $(\%)$ \\
\hline 16384 & 1976 & 4.35 \\
34610 & 2062 & 1985 \\
66542 & 1985 & \\
\hline
\end{tabular}

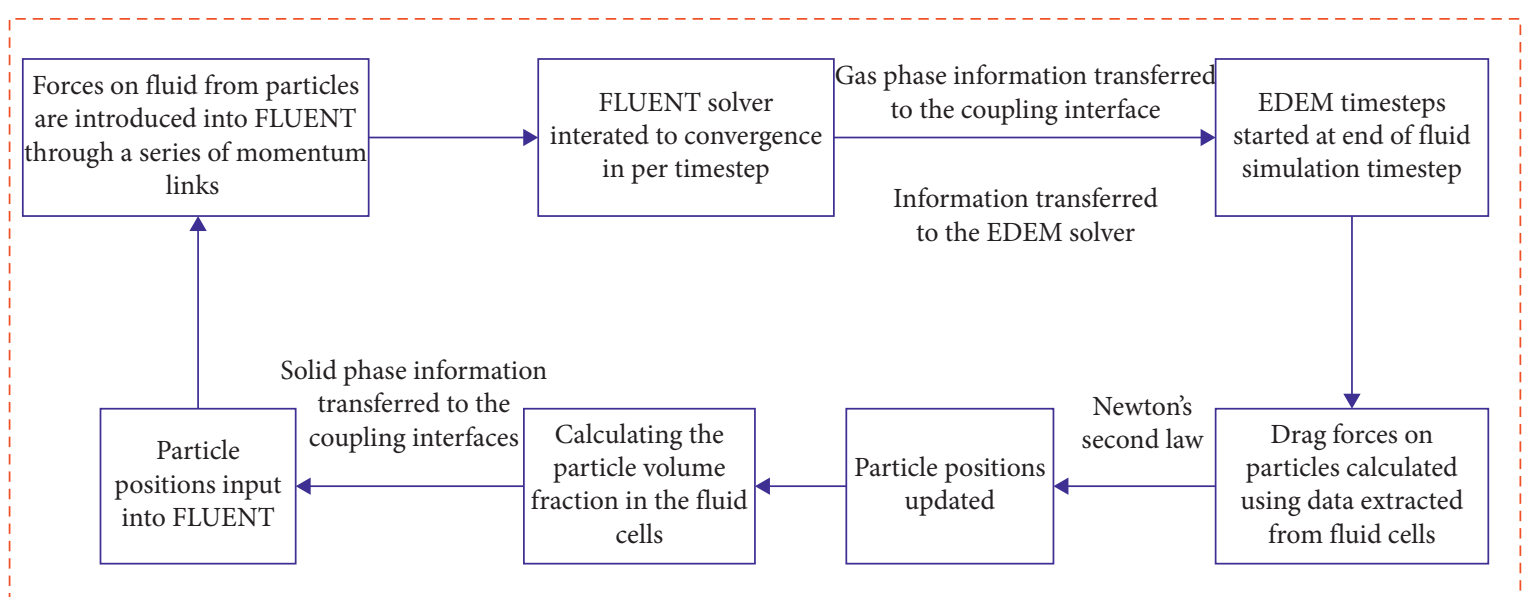

FIGURE 2: The process of FLUENT-EDEM coupling method.

where $\ddot{v}_{i}$ and $\ddot{\theta}_{i}$ are particle $i$ acceleration and angle velocity. $m_{i}$ and $I_{i}$ are particle $i$ mass and inertia moment. $F_{i}$ and $M_{i}$ are accumulated force and accumulated moment.

In this work, the Hertz-Mindlin nonsliding contact model was adopted [17].

The coal particle is subjected to drag force, gravity, particle-particle interaction force, buoyancy, pressure gradient force, lift force, virtual mass force, and other forces. Pressure gradient force, lift force, and virtual mass force are negligible compared with drag force, gravity, and coal particle-coal particle force. Therefore, the force Fi of coal particle can be expressed as previously reported [18]:

$$
F_{i}=m_{i} g+f_{p-g, i}+\sum_{j=1}^{k_{i}}\left(f_{c, i j}+f_{d, i j}\right) .
$$


The Grun, Wen, and Yu drag force model was used to describe the drag force $f_{p-g, i}[19]$ :

$$
\begin{aligned}
f_{c, i j} & =f_{n, i j}^{c}+f_{t, i j}^{c}, \\
f_{n, i j}^{c} & =\frac{4}{3} E^{*} \sqrt{R^{*}} \sigma_{n}^{1.5}, \\
f_{t, i j}^{c} & =-2 \sqrt{\frac{5}{6} \beta \sqrt{S_{n} m^{*}} v_{n}^{\text {rel }},} \\
\beta & =\frac{\ln e}{\sqrt{\ln ^{2} e+\pi^{2}}}, \\
S_{n} & =2 Y^{*} \sqrt{R^{*} \delta_{n}},
\end{aligned}
$$

where $f_{n, i j}^{c}$ is normal contact force, $f_{t, i j}^{c}$ is tangential contact force, $E^{*}$ is equivalent Young's modulus, $R^{*}$ is coal particle equivalent radius, $\delta_{n}$ is normal overlap, $m^{*}$ is equivalent mass, $v_{n}^{\text {rel }}$ is normal component of relative velocity, $e$ is restitution coefficient, $S_{n}$ is normal stiffness, and $\beta$ is damping coefficient:

$$
\begin{aligned}
f_{d, i j} & =f_{n, i j}^{d}+f_{t, i j}^{d}, \\
f_{n, i j}^{d} & =-S_{t} \delta_{t}, \\
S_{t} & =8 G^{*} \sqrt{R^{*} \delta_{n}}, \\
f_{t, i j}^{d} & =-2 \sqrt{\frac{5}{6}} \beta \sqrt{S_{t} m^{*}} v_{t}^{\text {rel }},
\end{aligned}
$$

where $f_{t, i j}^{d}$ is tangential damping force, $f_{n, i j}^{d}$ is normal damping force, $\delta_{t}$ is tangential overlap, $m^{*}$ is equivalent mass, $v_{t}^{\text {rel }}$ is relative velocity tangential component, $S_{t}$ is tangential stiffness, and $G^{*}$ is equivalent shear modulus.

Rolling friction torque $T_{i}$ is

$$
T_{i}=-\mu_{t} F_{t} R_{i} \omega_{i},
$$

where $\mu_{t}$ is rolling friction coefficient, $F_{n}$ is coal particle-surface normal contact force, $R_{i}$ is distance from coal particle sphere center to contact point, and $\omega_{i}$ is particle angular velocity.

3.3. Gas Phase Governing Equation. The RNG $k$ - $\varepsilon$ turbulence model was used to solve the gas phase governing equations. Both the turbulent kinetic energy and the discrete rate adopted the second-order upwind scheme; the pressure term dispersion scheme was PRESTO, the momentum term discrete scheme was QUICK, and the pressure-velocity coupling applied the SIMPLE algorithm.

3.4. Time Step Setting. The time step was determined by Rayleigh time step $T_{R}$ :

$$
T_{R}=(0.1631 \sigma+0.8766)^{-1} \pi d_{p} \sqrt{\frac{\rho_{p}}{G}},
$$

where $\sigma$ is Poisson's ratio and $G$ is coal particle shear modulus.

3.5. Simulation Conditions Setting. Setting of gas phase conditions: according to the empirical formula, when the coal particle size is $1 \mathrm{~mm}$, its suspension velocity is $5.97 \mathrm{~m} / \mathrm{s}$. For the pneumatic conveying empirical process of the coal particle in a suspended transport state, the air velocity needs to be 2 to 2.5 times the coal particle suspension velocity. Therefore, the gas velocity is selected as $15 \mathrm{~m} / \mathrm{s}, 20 \mathrm{~m} / \mathrm{s}$, and $25 \mathrm{~m} / \mathrm{s}$. The velocity is evenly distributed perpendicular to the entrance and the exit condition is the pressure boundary. The wall has no slip boundary conditions and the time step is $3 e-05 \mathrm{~s}$.

Setting of coal particle phase conditions: the method of dynamically generating coal particle was adopted, assuming that coal particle flows into the three fluid holes uniformly into the bit-drilling rod $(0 \mathrm{~m} \sim 5 \mathrm{~m})$. Taking $\varnothing 94 \mathrm{~mm}$ PDC bit as an example, the density of coal particle is $1450 \mathrm{~kg} / \mathrm{m}^{3}$, and the mass of coal particle produced when drilling $1 \mathrm{~m}$ is about $10 \mathrm{~kg}$. The mass flow rate of coal shavings in a single fluid hole is then taken as $0.02 \mathrm{~kg} / \mathrm{s}, 0.03 \mathrm{~kg} / \mathrm{s}, 0.04 \mathrm{~kg} / \mathrm{s}$, and $0.05 \mathrm{~kg} / \mathrm{s}$ (expressed in terms of single hole coal shavings mass flow rate), corresponding to the total coal mass flow rate of $3.6 \mathrm{~kg} / \mathrm{min}, 5.4 \mathrm{~kg} / \mathrm{min}, 7.2 \mathrm{~kg} / \mathrm{min}$, and $9 \mathrm{~kg} / \mathrm{min}$, respectively. The time step of coal particle phase is $6 e-07 \mathrm{~s}$. The specific simulation conditions are shown in Table 2 . The physical property parameters such as coal particle and wall surface are shown in Table 3.

\section{Results and Discussion}

4.1. Model Validation. In order to verify the accuracy of the CFD-DEM calculation method and turbulence model selected in this work, refer to the relevant experimental data of the horizontal dilute phase pneumatic conveying of Naveh [20] for verification. Pressure drop is main parameters for pneumatic conveying and is used for validation in this study. Figure 3 shows the pressure drop of simulated results under different gas velocities, which were compared with experimental pressure drop data by Naveh.

4.2. Coal-Gas Flow in the Drilling Bit-Rod Integral Structure of $0 m \sim 5 \mathrm{~m}$. In this work, 12 cases were carried out at $3 \mathrm{~s}$ for each case. The flow pattern of coal particle in the bit-drilling rod $(0-5 \mathrm{~m})$ depicts the acceleration and deposition characteristics of coal particle at the initial stage of entering the bit, which intuitively reflects the coal particle in the drilling and the propensity to block the pipeline inside the rod. The pattern of coal particle flowing out of the drilling rod area showed the acceleration characteristics of coal particle under different conditions and ability of transporting the coal particles. The distribution of the number of coal particles along their flow direction at the same gas velocity particle flow rate and different gas velocities further reflects the gas velocity's ability of transporting coal particles and their flow patterns. The velocity of coal particle is obtained and the proportion of different velocities indicates the influence of 
TABLE 2: Simulation cases setting.

\begin{tabular}{lcc}
\hline Case & Coal mass flow rate $\left(\mathrm{kg} \cdot \mathrm{s}^{-1}\right)$ & Gas velocity $\left(\mathrm{m} \cdot \mathrm{s}^{-1}\right)$ \\
\hline 1 & $0.02 \times 3$ & 15 \\
2 & $0.02 \times 3$ & 20 \\
3 & $0.02 \times 3$ & 25 \\
4 & $0.03 \times 3$ & 15 \\
5 & $0.03 \times 3$ & 20 \\
6 & $0.03 \times 3$ & 25 \\
7 & $0.04 \times 3$ & 15 \\
8 & $0.04 \times 3$ & 20 \\
9 & $0.04 \times 3$ & 25 \\
10 & $0.05 \times 3$ & 15 \\
11 & $0.05 \times 3$ & 20 \\
12 & $0.05 \times 3$ & 25 \\
\hline
\end{tabular}

TABle 3: Physical parameters of coal and wall.

\begin{tabular}{lcc}
\hline Parameter & Unit & Value \\
\hline Coal density & $\mathrm{km} \cdot \mathrm{m}^{-3}$ & 1450 \\
Coal Poisson's ratio & - & 0.201 \\
Coal shear modulus & $\mathrm{Pa}$ & $1.4 e 9$ \\
Coal particle radius & $\mathrm{mm}$ & 1 \\
Steel density & $\mathrm{km} \cdot \mathrm{m}^{-3}$ & 7400 \\
Steel Poisson's ratio & - & 0.25 \\
Steel shear modulus & $\mathrm{Pa}$ & $8.24 e 10$ \\
Coal restitution coefficient & - & 0.5 \\
Coal static friction coefficient & - & 0.6 \\
Coal rolling friction coefficient & - & 0.05 \\
Coal steel restitution coefficient & - & 0.5 \\
Coal steel static friction coefficient & - & 0.4 \\
Coal steel rolling friction coefficient & - & 0.05 \\
\hline
\end{tabular}

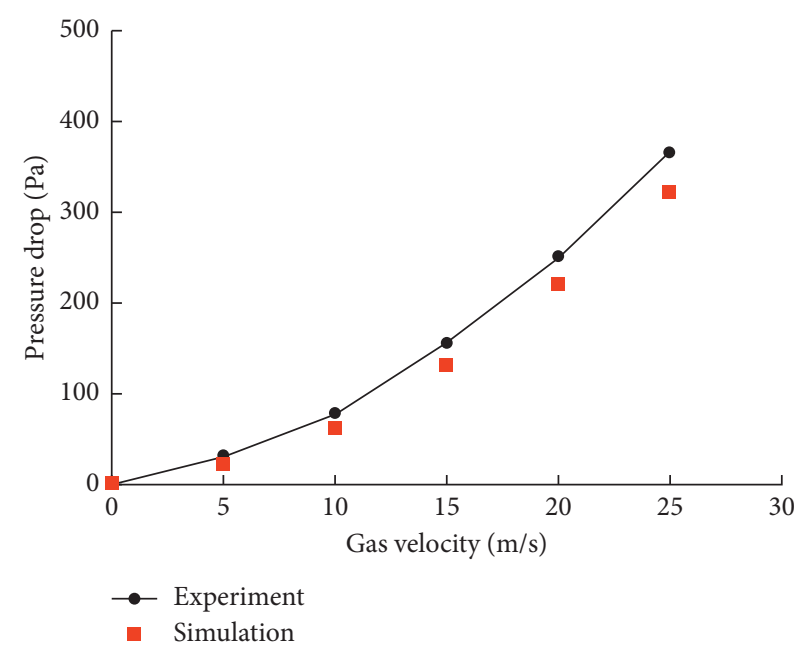

Figure 3: Comparison of pressure drop at different gas velocities $(d=1.44 \mathrm{~mm}$ and $D=52.5 \mathrm{~mm})$.

gas velocity on the acceleration process of coal particle and depicts the flow pattern of coal particle at different positions. Therefore, at the same gas velocity, the output coal cuttings have different flow rate bit-drilling rod $0-0.5 \mathrm{~m}$ of coal particle flow pattern ( $Z$ direction $0 \mathrm{~m} \sim 0.5 \mathrm{~m}$ in this model), flowing out of the drilling rod area (at this time in the model, the direction of coal particle in $Z$ direction is $4.5 \mathrm{~m} \sim 5 \mathrm{~m}$ ); the same coal particle flow rate has different gas velocity, number of coal particles at different positions, velocity of coal particle obtained, and proportion of different velocities.

After the gas flows into the bit-drilling rod $(0-5 \mathrm{~m})$, the coal particle influences the gas flow. Gas velocity is an important parameter to characterize the airflow. The change of gas velocity reflects the influence of coal particle on airflow. The influence of coal particle on the airflow is most obvious in the bit-gas velocity rod $(0-0.5 \mathrm{~m})$ section. Therefore, the gas velocity contour in the bit-gas velocity rod $(0-0.5 \mathrm{~m})$ segment $(0-0.5 \mathrm{~m}$ in $Z$ direction in this model) at different coal particle flow rates in the gas phase is revealed.

\subsection{Coal-Gas Flow in the Drilling Bit-Rod Integral Structure of $0-0.5 \mathrm{~m}$}

(1) The coal-gas flow characteristic in the bit-drilling rod $(0 \mathrm{~m} \sim 0.5 \mathrm{~m})$ section under different mass flow rates of coal particles at gas velocity of $15 \mathrm{~m} / \mathrm{s}$ is as shown in Figure 4.

When the coal particle entered into the bit-rod through fluid holes under mass flow rate of $0.02 \mathrm{~kg} / \mathrm{s}$, an obvious bottom flow characteristic along the flow direction appeared, and a small amount of coal particle accumulated at the end. When the coal particle mass flow rate was $0.03 \mathrm{~kg} / \mathrm{s}$, the amount of coal particle increased at the bottom of the drill pipe, the highest layer thickness point appeared at about $0.33 \mathrm{~m}$, the accumulation of coal particle at the end of the drill bit increased, the flow of coal particle was the highest after the layer thickness point, and part of the coal particle started to accelerate and formed a suspension. When the coal particle mass flow rate of reached $0.04 \mathrm{~kg} / \mathrm{s}$, the highest layer thickness point moved in the direction of flow. The thickness of the coal particle layer was thicker than that of $0.03 \mathrm{~kg} / \mathrm{s}$, and a small amount of coal particle in the upper part of the drilling rod was suspended. When the coal particle mass flow rate reached $0.05 \mathrm{~kg} / \mathrm{s}$, the accumulation of coal particles at the end of the drilling rod and the thickness of the coal particles further increased, and the thickest layer of coal particle advanced again along the direction of flow.

When the gas flowed into the bit, a high-velocity strip formed at the axial center of the bit with the coal particle mass flow rate of $0.02 \mathrm{~kg} / \mathrm{s}$. Along the flow direction, the strip in the high-velocity zone was distributed on the upper part of the drilling rod and its width gradually decreased to $0.30 \mathrm{~m}$. There was a reverse velocity zone within a certain range near the end of the bit. The strip range of the high-velocity zone was extended along the flow direction, and a thin strip-shaped high-velocity zone was formed on the upper part of the drilling rod, and the range of the velocity zone in the opposite direction of the end of the bit was reduced when the coal particle mass flow rate was $0.03 \mathrm{~kg} / \mathrm{s}$. When the coal mass flow rate increased to $0.04 \mathrm{~kg} / \mathrm{s}$ and $0.05 \mathrm{~kg} / \mathrm{s}$, the band range 


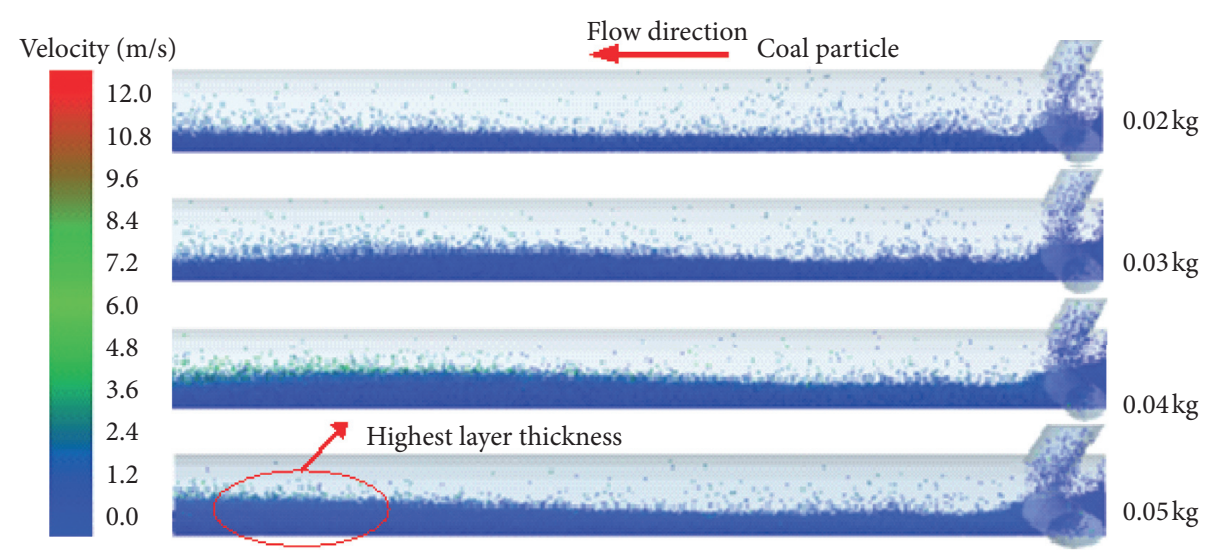

(a)

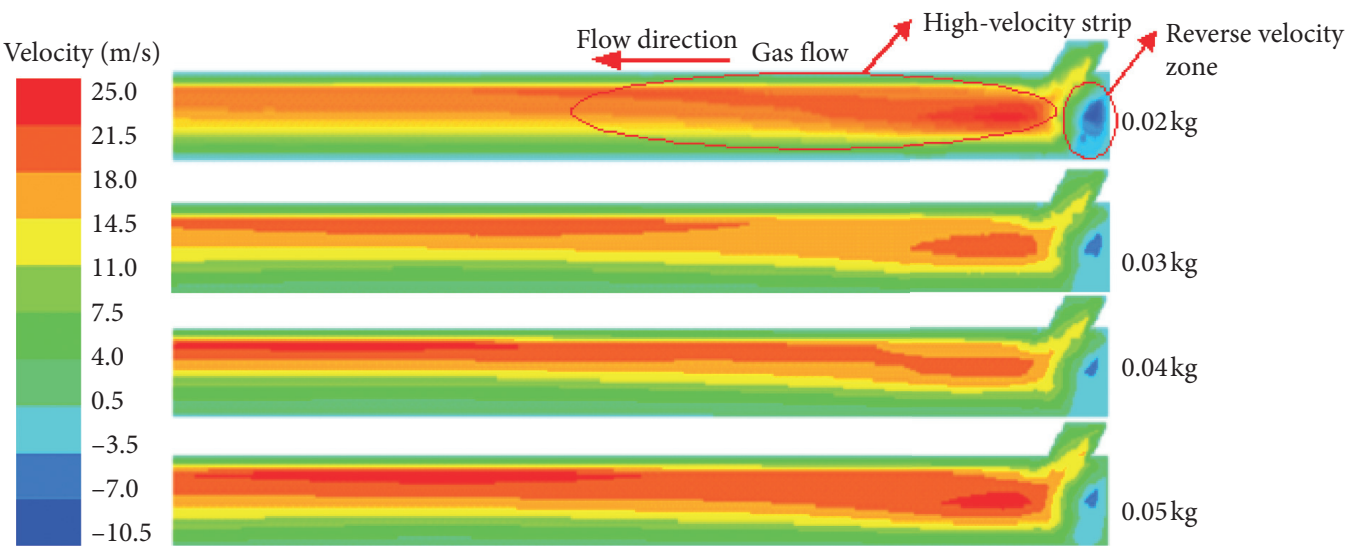

(b)

FIgURE 4: The coal-gas flow characteristic in drilling bit-rod integral structure $0 \sim 0.5 \mathrm{~m}$ under gas velocity of $15 \mathrm{~m} / \mathrm{s}(t=3 \mathrm{~s})$.

of the gas high-velocity area increased, and the reverse direction velocity area slightly changed.

(2) The coal-gas flow states at drilling bit-rod integral structure $0 \mathrm{~m} \sim 0.5 \mathrm{~m}$ section are shown in Figure 5, when the gas velocity was $20 \mathrm{~m} / \mathrm{s}$ at different coal particle mass flow rates.

When the coal particle flow rate was $0.02 \mathrm{~kg} / \mathrm{s}$, there was a higher particle concentration at the $0 \mathrm{~m}$ to $0.25 \mathrm{~m}$ section. The coal particle concentration decreased along the flow direction; the movement and suspension motion of coal particle became more dispersed and pronounced, respectively. There was a small amount of coal particle suspension movement at the end of the drilling bit. When the coal particle mass flow rate was $0.03 \mathrm{~kg} / \mathrm{s}$, the coal particle of the highest thickness point in the drilling rod was at $0.1 \mathrm{~m} \sim 0.15 \mathrm{~m}$ and pipe bottom flow occurred. The accumulation of coal particle at the end of the drilling bit increased along the flow direction. After the coal particles flowed past the highest layer thickness point, the amount of suspended coal particles increased and their concentration in the upper part of the drilling rod became low, and the concentration of coal particles in the lower part became high. The thickness of coal particles at the bottom of the pipe changed slightly along the flow direction. At a coal particle mass flow rate of $0.04 \mathrm{~kg} / \mathrm{s}$, the highest layer thickness point appeared at $0.1 \mathrm{~m} \sim 0.15 \mathrm{~m}$, the amount of suspended coal particles decreased, the thickness of the coal particle layer increased, and the accumulation of coal particle at the end of the drilling bit increased.

Compared to coal particle mass flow rate of $0.04 \mathrm{~kg} / \mathrm{s}$, the coal particle accumulation at the end of the drilling bit and the thickness of the coal particle layer increased under coal particle mass flow rate of $0.05 \mathrm{~kg} / \mathrm{s}$.

When the gas flowed into the drilling bit, a highvelocity strip formed at its axial center and a reverse velocity range appeared near its end when the coal particle mass flow rate was $0.02 \mathrm{~kg} / \mathrm{s}$. When the coal particle mass flow rate was $0.03 \mathrm{~kg} / \mathrm{s}$, the length of the strip in the high-velocity zone extended to $0.4 \mathrm{~m}$ and the zone became larger, while the range of the velocity zone decreased in the opposite direction. When the coal particle mass flow rate increased to $0.04 \mathrm{~kg} / \mathrm{s}$ and $0.05 \mathrm{~kg} / \mathrm{s}$, respectively, the high-velocity zones extended to $0.5 \mathrm{~m}$, and the strip widths were wider than those in the opposite direction, while the velocity zone slightly changed in the reverse direction. 


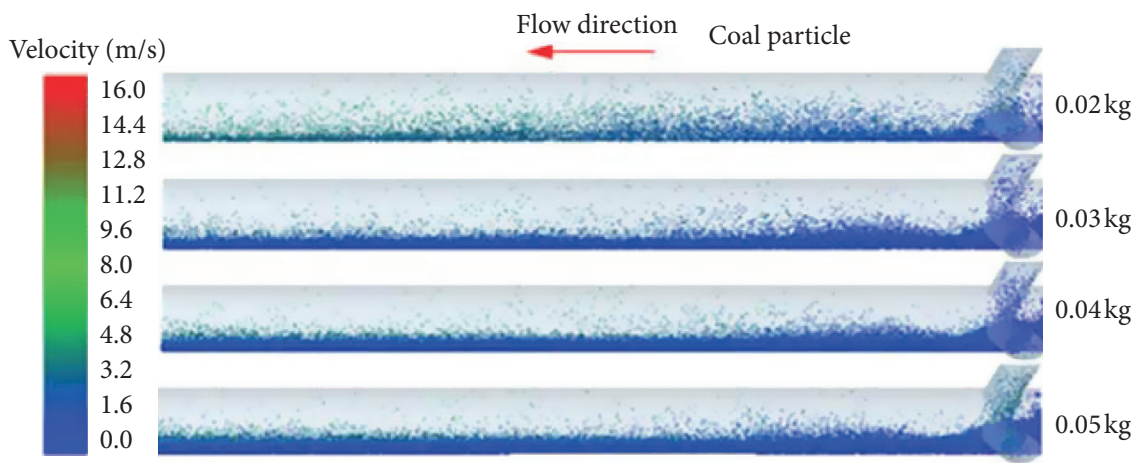

(a)

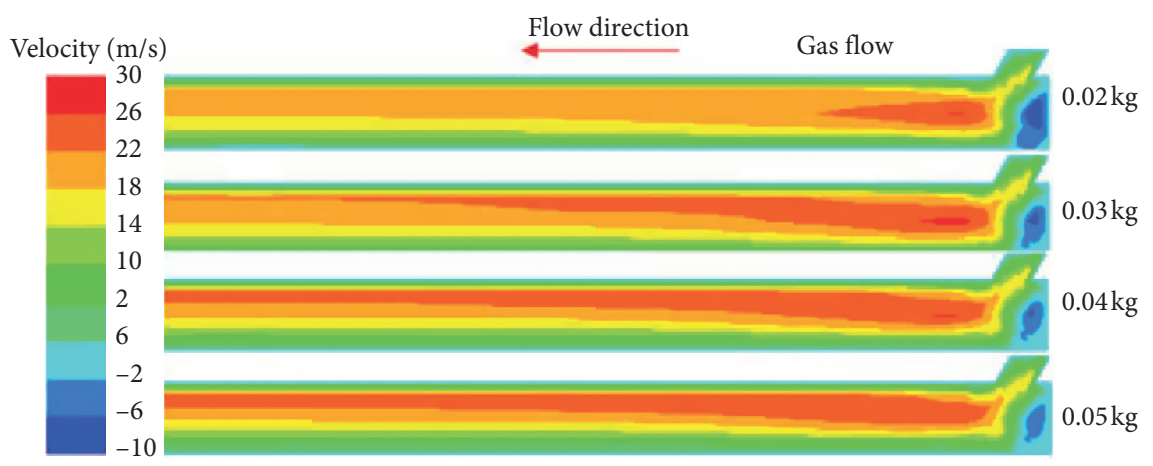

(b)

Figure 5: The coal-gas flow characteristic in drilling bit-rod integral structure $0 \sim 0.5 \mathrm{~m}$ under gas velocity of $20 \mathrm{~m} / \mathrm{s}(t=3 \mathrm{~s})$.

(3) The coal-gas flow states at drilling bit-rod integral structure $0 \mathrm{~m} \sim 0.5 \mathrm{~m}$ section are shown in Figure 6, when the gas velocity was $25 \mathrm{~m} / \mathrm{s}$ at different coal particle mass flow rates.

When the coal particle mass flow rate was $0.02 \mathrm{~kg} / \mathrm{s}$, the movement of the coal particle in the drilling rod became more dispersed, and there was a small accumulation of coal particles at its end. At a coal particle mass flow rate of $0.03 \mathrm{~kg} / \mathrm{s}$, a typical pipe bottom flow appeared, and the accumulation of coal particles at the end of the drilling bit increased. The thickness of coal particles at the bottom of the pipe gradually decreased along the flow direction. When the coal particle mass flow rate was $0.04 \mathrm{~kg} / \mathrm{s}$, the bottom flow characteristics of the pipe strengthened. When the coal particle mass flow rate reached $0.05 \mathrm{~kg} / \mathrm{s}$, the accumulation of coal particle at the end of the drilling rod further increased.

A high-velocity strip formed at the axial center of the drilling bit when the gas flowed into it under coal particle mass flow rate of $0.02 \mathrm{~kg} / \mathrm{s}$. The high-velocity zone strip was distributed along the flow direction on the upper part of the drilling rod, and its width decreased gradually. There was a range of reverse velocity within a certain range near the end of the drilling bit. When the coal particle mass flow rate was $0.03 \mathrm{~kg} / \mathrm{s}$, the width of the strip in the high-velocity zone became wider than that under $0.02 \mathrm{~kg} / \mathrm{s}$, while the change in velocity zone in the opposite direction was not apparent. When the airflow flowed to $0.5 \mathrm{~m}$ in the flow direction, the coal particle mass flow rate increased to $0.04 \mathrm{~kg} / \mathrm{s}$ and
$0.05 \mathrm{~kg} / \mathrm{s}$, respectively, and the strip width of the high-velocity zone became wider than that of the former, while the reverse direction velocity zone was slightly decreased.

\subsection{Coal Particle Flow in Drilling Rod at $4.5 \mathrm{~m} \sim 5.0 \mathrm{~m}$}

(1) The states of coal-air flow at $4.5 \mathrm{~m} \sim 5 \mathrm{~m}$ section of the drilling rod under different coal particle mass flow rates are as shown in Figure 7 at gas velocity of $15 \mathrm{~m} / \mathrm{s}$. When the coal particle mass flow rate was $0.02 \mathrm{~kg} / \mathrm{s}$, a small amount of coal particles flew through this section, and some of them were suspended in motion. When the coal particle mass flow rate reached $0.03 \mathrm{~kg} / \mathrm{s}$, the number of coal particles increased. A small amount of coal particles was distributed on the upper part of the drilling rod. When the coal particles mass flow rate reached $0.04 \mathrm{~kg} / \mathrm{s}$, both the number of coal particles that flowed through this section and those suspended in the upper part of the drilling rod increased, and the bottom flow characteristics were obvious. When the coal particles mass flow rate reached $0.05 \mathrm{~kg} / \mathrm{s}$, the characteristics of the bottom flow of the pipe were more obvious, and the number of coal particles suspended in the upper part of the drilling rod slightly increased.

(2) The coal-air flow states of the $4.5 \mathrm{~m} \sim 5 \mathrm{~m}$ section of the drilling rod under different coal particle mass flow rates are as shown in Figure 8 when the gas velocity was $20 \mathrm{~m} / \mathrm{s}$. 


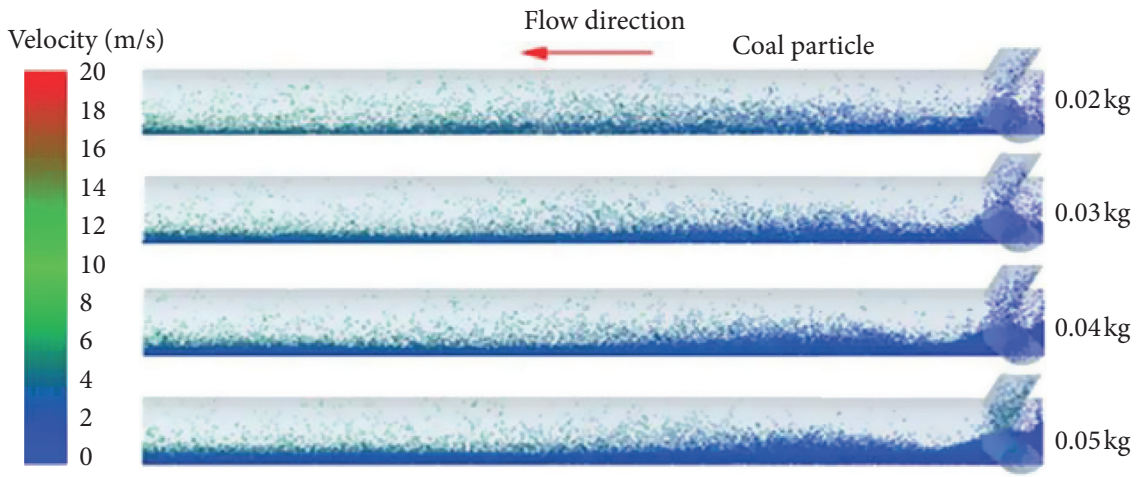

(a)

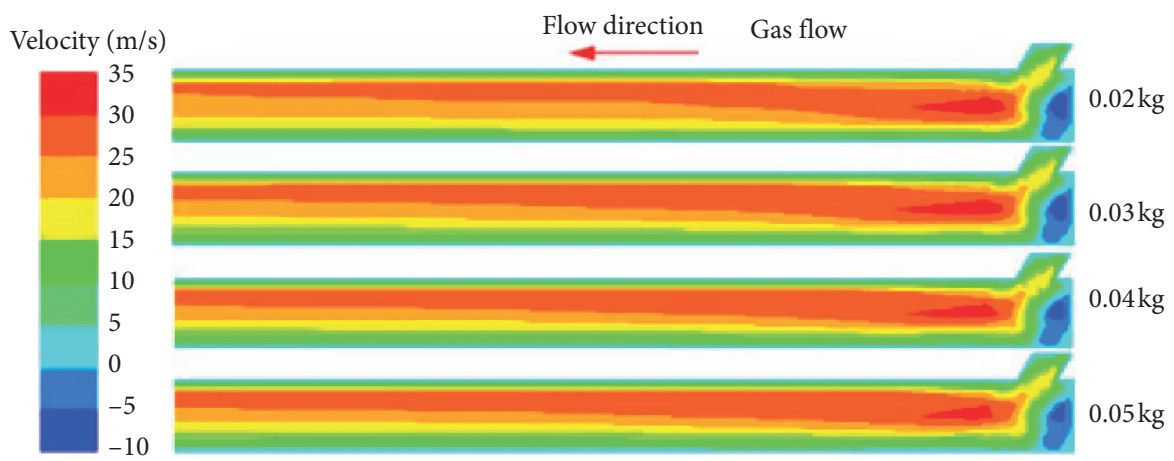

(b)

FIGURE 6: The coal-gas flow characteristic in drilling bit-rod integral structure $0 \sim 0.5 \mathrm{~m}$ under gas velocity $25 \mathrm{~m} / \mathrm{s}(t=3 \mathrm{~s})$.

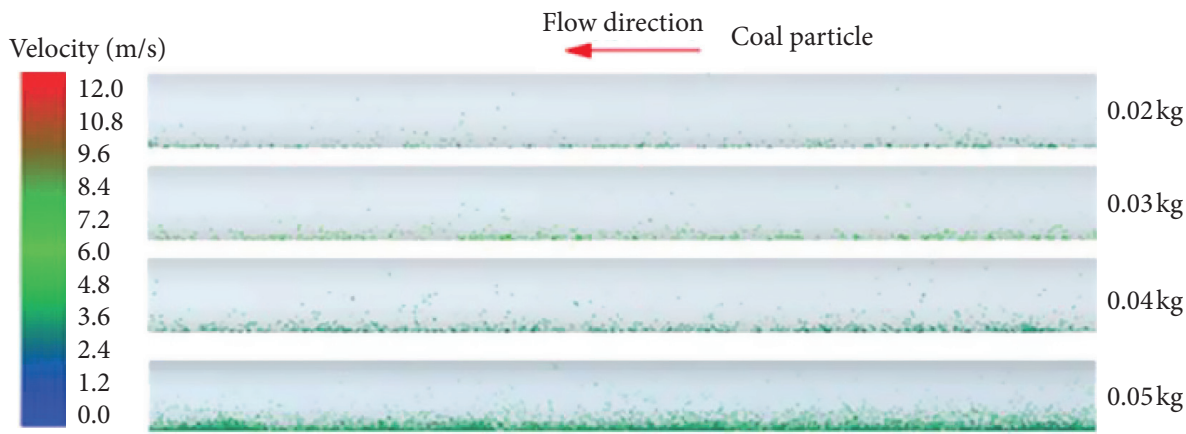

Figure 7: The coal-gas flow characteristic in drilling rod at $4.5 \sim 5.0 \mathrm{~m}$ under gas velocity $15 \mathrm{~m} / \mathrm{s}(t=3 \mathrm{~s})$.

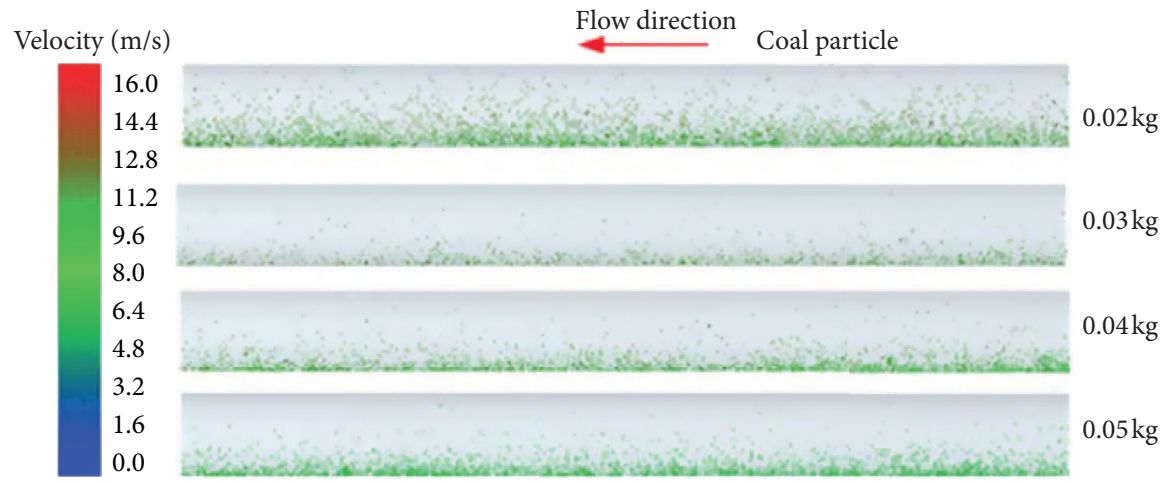

Figure 8: The coal-gas flow characteristic in drilling rod at $4.5 \sim 5.0 \mathrm{~m}$ under gas velocity of $20 \mathrm{~m} / \mathrm{s}(t=3 \mathrm{~s})$. 
When the coal particle mass flow rate was $0.02 \mathrm{~kg} / \mathrm{s}$, all the coal particles were approximately in suspension flow state and the coal particle velocity was around $10 \mathrm{~m} / \mathrm{s}$. When the coal particle mass flow rate reached $0.03 \mathrm{~kg} / \mathrm{s}$, the amount and velocity of coal particles flowing through this part decreased compared with those at $0.02 \mathrm{~kg} / \mathrm{s}$ and the motion of coal particles was distributed in the middle and lower part of the drilling rod. When the coal particle mass flow rates were $0.04 \mathrm{~kg} / \mathrm{s}$ and $0.05 \mathrm{~kg} / \mathrm{s}$, the amount of coal particles flowing through this part changed slightly, while the particle velocity increased.

(3) The coal-air flow states of the $4.5-5 \mathrm{~m}$ section of the drilling rod under different coal particle mass flow rates are as shown in Figure 9 when the gas velocity was $25 \mathrm{~m} / \mathrm{s}$.

When the coal particle mass flow rates were $0.02 \mathrm{~kg} / \mathrm{s}$ and $0.03 \mathrm{~kg} / \mathrm{s}$, the coal particles in the drilling rod were in a suspended flow motion, and the high-velocity coal particle suspension motion was at the upper part of the drilling rod. When the coal particle mass flow rate reached $0.04 \mathrm{~kg} / \mathrm{s}$ and $0.05 \mathrm{~kg} / \mathrm{s}$, the coal particles in the drill pipe were mostly in a suspended state, while a small quantity of low-velocity coal particles moved along the direction of the bottom of the rod, indicating a slight bottom flow. Figures 8-10 showed the flow patterns of coal particles in the $4.5 \mathrm{~m}-5 \mathrm{~m}$ section along the flow direction under different conditions. This section reflects the flow pattern after the coal particle flowed into the drilling rod after an acceleration distance of $4 \mathrm{~m}$.

When the gas velocity was $15 \mathrm{~m} / \mathrm{s}$, the amount of coal particle at $0-0.5 \mathrm{~m}$ gradually increased with the coal particle mass flow rate that increased from $0.02 \mathrm{~kg} / \mathrm{s}$ to $0.05 \mathrm{~kg} / \mathrm{s}$, while the energy obtained by a single coal particle decreased under the same gas velocity. When the coal particles reached the $4.5-5.0 \mathrm{~m}$ section, the coal particle velocity was higher and more evenly distributed on the drilling rod cross section when the coal particle mass flow rate was $0.02 \mathrm{~kg} / \mathrm{s}$. As the coal particle mass flow rate increased, the bottom flow characteristics became obvious and the coal particle velocity was lower. As the coal particle mass flow rate increases, the coal particle flow state characteristics at the tube bottom gradually strengthen. Only a part of high-velocity coal particle was distributed in the upper part of the drilling rod. When the gas velocity increased to $20 \mathrm{~m} / \mathrm{s}$ and $25 \mathrm{~m} / \mathrm{s}$, respectively, the kinetic energy of a single coal particle increased and more coal particles accelerated to the suspension velocity. Therefore, the suspension characteristics of the coal particles increased with the increasing gas velocity in the range of $4.5-5 \mathrm{~m}$ for the drilling rod.

4.5. Gas Flow in the Drilling Bit-Rod Integral Structure of $0 \mathrm{~m} \sim 0.5 \mathrm{~m}$. There were high-velocity area and reverse velocity area in the opposite direction of the $0-0.5 \mathrm{~m}$ section of the drilling rod, as shown in Figure 10. The three fluid holes of the drilling bit were evenly distributed along the circumference, and the coal-gas flowed into the drilling bit and converged at the axis of the drill rod, forming a high-velocity area. The cross-sectional area of the drilling bit fluid hole was smaller than that of the drilling rod. When the gas flowed into the drilling bit, a secondary flow was generated in the drilling bit by part of the gas flow. Therefore, a reverse velocity area formed at the center of the end. The range of high-velocity area expanded with increase in coal particle mass flow rate, while the range of the reverse velocity area decreased.

Along the flow direction, the high-velocity strip was in the upper region of the drilling rod. This was because the coal particles flowed into the drilling bit at lower velocity and accelerated due to the drag and gravitational forces. In the zone of $0 \mathrm{~m}$ to $0.5 \mathrm{~m}$, there was a bottom flow for the selfgravity. The flow channel of the gas moved upward while the high-velocity area moved forward along the flow direction with increasing coal particles as shown in Figures 6-8. At the same gas velocity, with continuous acceleration of coal particles, the flow pattern transitioned from bottom flow to uniform suspended flow. Consequently, the impact of the bottom coal on the air flow gradually reduced, and the highvelocity band of gas flow gradually disappeared while the distribution of the air flow field changed to the distribution characteristics of "high center, low wall." As the coal particle mass flow rate increased, its influence on the air flow gradually increased within $0 \mathrm{~m} \sim 0.5 \mathrm{~m}$, leading to extension and expansion of the range of high-velocity zone along the direction of flow. The range of the reverse velocity area gradually reduced for the coal particle mass flow rate of the same gas velocity and thus increased the influence of coal particle on the gas flow field and weakened the secondary flow intensity of the gas flow at the end of the drilling bit. Therefore, the influence of coal particle on the gas phase flow field cannot be neglected.

4.6. Coal Flow in Drilling Bit-Rod Integral Structure of $0 \mathrm{~m} \sim 5 \mathrm{~m}$. To further analyze the particle flow characteristics of the drilling bit-rod integral structure of $0 \sim 5 \mathrm{~m}$, four aspects including the proportion, velocity, length of the bottom flow characteristic, and the acceleration distance of the suspension of coal particles at different locations were studied.

\subsubsection{Proportion of Coal Particle at Different Locations.} The coal particle number distribution along the flow direction could reflect the acceleration and movement characteristics of coal particles under this condition, as well as the ability of transporting coal particles under different gas velocities, and could also provide the basis for determining the flow pattern of coal particle. The ratio of the number of coal particles at different positions is defined as the ratio of the number of coal particles at a certain position to the total number of coal particles near the drilling bit under steady flow. The statistical results are as shown in Figure 11.

Figure 11 shows that when the coal particle mass flow rate was $0.02 \mathrm{~kg} / \mathrm{s}$, the proportion of coal particle in the $0-0.5 \mathrm{~m}$ section to the total coal particle was $44.67 \%$ under gas velocity of $15 \mathrm{~m} / \mathrm{s}$. When the gas velocity increased to $20 \mathrm{~m} / \mathrm{s}$, the proportion of coal particle decreased to $32.48 \%$, 


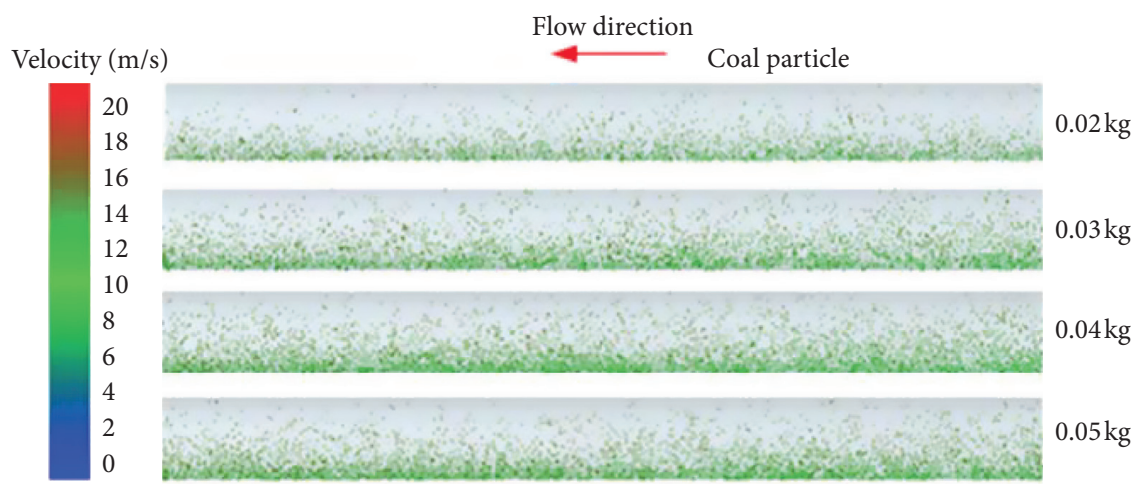

Figure 9: The coal-gas flow characteristic in drilling rod $4.5 \sim 5.0 \mathrm{~m}$ under gas velocity $25 \mathrm{~m} / \mathrm{s}(t=3 \mathrm{~s})$.

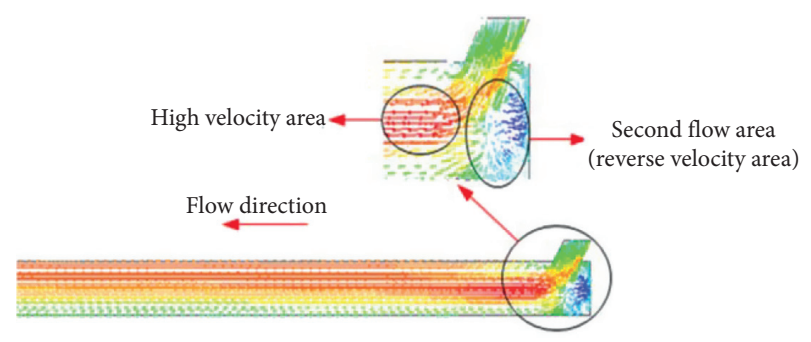

Figure 10: The gas phase flow vector of drilling bit-rod integral structure of $0 \sim 0.5 \mathrm{~m}$.

which was $27.27 \%$ lower than that at $15 \mathrm{~m} / \mathrm{s}$. At a gas velocity increase of $25 \mathrm{~m} / \mathrm{s}$, the proportion of coal particles in the $0 \mathrm{~m} \sim 0.5 \mathrm{~m}$ section was $20.92 \%$ in comparison to the total coal particles. This was also a reduction of $53.17 \%$ and $35.60 \%$ compared with $15 \mathrm{~m} / \mathrm{s}$ and $20 \mathrm{~m} / \mathrm{s}$, respectively.

Figure 11 shows that when the coal particle mass flow rate was $0.03 \mathrm{~kg} / \mathrm{s}$, the proportion of coal particle in the $0 \mathrm{~m} \sim 0.5 \mathrm{~m}$ section to the total coal particle was $57.98 \%$ under a gas velocity of $15 \mathrm{~m} / \mathrm{s}$. On the one hand, when the gas velocity increased to $20 \mathrm{~m} / \mathrm{s}$, the proportion of coal particle decreased to $40.72 \%$, which was $29.27 \%$ lower than that at $15 \mathrm{~m} / \mathrm{s}$. On the other hand, when the gas velocity increased to $25 \mathrm{~m} / \mathrm{s}$, the proportion of coal particle in the $0 \mathrm{~m} \sim 0.5 \mathrm{~m}$ section was $28.55 \%$ of the total coal particle. Thus, the proportion of coal particles reduced by $50.7 \%$ and $29.89 \%$ compared with those under $15 \mathrm{~m} / \mathrm{s}$ and $20 \mathrm{~m} / \mathrm{s}$, respectively.

When the coal particle mass flow rate was $0.04 \mathrm{~kg} / \mathrm{s}$, the proportion of coal particle in the $0 \mathrm{~m} \sim 0.5 \mathrm{~m}$ section to the total coal particle was $76.49 \%$ under a gas velocity of $15 \mathrm{~m} / \mathrm{s}$. When the gas velocity increased to $20 \mathrm{~m} / \mathrm{s}$, the proportion of coal particle decreased to $41.34 \%$, which was $45.96 \%$ lower than that at $15 \mathrm{~m} / \mathrm{s}$; when the gas velocity increased to $25 \mathrm{~m} /$ $\mathrm{s}$, the proportion of coal particles in the $0 \mathrm{~m} \sim 0.5 \mathrm{~m}$ section to the total coal particles was only $31.83 \%$. Thus, the proportion of coal particles reduced by $58.38 \%$ and $22.98 \%$ compared with those under $15 \mathrm{~m} / \mathrm{s}$ and $20 \mathrm{~m} / \mathrm{s}$, respectively.

When the coal particle mass flow rate was $0.05 \mathrm{~kg} / \mathrm{s}$, the proportion of coal particles in the $0 \mathrm{~m} \sim 0.5 \mathrm{~m}$ section to the total coal particle was $80.30 \%$ under gas velocity of $15 \mathrm{~m} / \mathrm{s}$. When the gas velocity increased to $20 \mathrm{~m} / \mathrm{s}$, the proportion of coal particles decreased to $46.0 \%$, which was $42.71 \%$ lower than that at $15 \mathrm{~m} / \mathrm{s}$; when the gas velocity increased to $25 \mathrm{~m} / \mathrm{s}$, the proportion of coal particles in the $0 \mathrm{~m} \sim 0.5 \mathrm{~m}$ section to the total coal particle was only $34.50 \%$. Therefore, the proportion of coal particles reduced by $57.04 \%$ and $25.01 \%$ compared with those at $15 \mathrm{~m} / \mathrm{s}$ and $20 \mathrm{~m} / \mathrm{s}$, respectively.

Coal particle distribution of drilling bit-rod integral structure in the $0 \mathrm{~m} \sim 0.5 \mathrm{~m}$ section of exhibited the following characteristics: the lower the gas velocity, the greater the amount of coal particles distributed in the drilling bit in $0 \mathrm{~m} \sim 0.5 \mathrm{~m}$ section under the same coal particle mass flow rate, and the distribution of coal particles gradually decreased along the flow direction. The coal particle in the $0 \mathrm{~m} \sim 0.5 \mathrm{~m}$ section was significantly reduced, and the distribution of coal particle along the flow direction tended to be balanced with the increase of gas velocity. The higher the gas velocity, the higher the the kinetic energy per unit mass of coal particles; thus, the coal particle moved fast inside the drilling rod.

4.6.2. Velocity of Coal Particles at Different Locations. The velocity distribution of coal particles at the same gas velocity and different coal particle mass flow rates is as shown in Figures 12-15.

Figure 12 shows that part of the coal particle velocity was in the range of $3 \mathrm{~m} / \mathrm{s}$ and only a small number of coal particles had a velocity of $3 \mathrm{~m} / \mathrm{s}$ to $4.5 \mathrm{~m} / \mathrm{s}$ in the $0 \mathrm{~m}$ to $0.5 \mathrm{~m}$ section having a gas velocity of $15 \mathrm{~m} / \mathrm{s}$. In the $1 \mathrm{~m} \sim 3 \mathrm{~m}$ section, the velocity of most coal particle was about $6 \mathrm{~m} / \mathrm{s}$, and the velocity of a few coal particles reached $7.5 \mathrm{~m} / \mathrm{s}$. Within the $3 \mathrm{~m} \sim 5 \mathrm{~m}$ section, the velocity of coal particles was mostly above $6 \mathrm{~m} / \mathrm{s}$, and the highest velocity realized was about $9 \mathrm{~m} / \mathrm{s}$.

When the gas velocity increased to $20 \mathrm{~m} / \mathrm{s}$, a small quantity of coal particles had a velocity of less than $3 \mathrm{~m} / \mathrm{s}$ in the $0-0.5 \mathrm{~m}$ section. The velocity of coal particles was mainly above $6 \mathrm{~m} / \mathrm{s}$ at $2 \mathrm{~m}$, and it increased to $12 \mathrm{~m} / \mathrm{s}$ at $5 \mathrm{~m}$.

When the gas velocity increased to $25 \mathrm{~m} / \mathrm{s}$, the number of coal particles having a velocity of less than $3 \mathrm{~m} / \mathrm{s}$ was further reduced in the $0 \mathrm{~m}$ to $0.5 \mathrm{~m}$ section. The velocity of coal particle was more than $6 \mathrm{~m} / \mathrm{s}$ at $2 \mathrm{~m}$, and it increased to more than $12 \mathrm{~m} / \mathrm{s}$ at $5 \mathrm{~m}$.

Figure 13 shows that when the gas velocity was $15 \mathrm{~m} / \mathrm{s}$, the coal particle velocity was less than $2.25 \mathrm{~m} / \mathrm{s}$ in the 


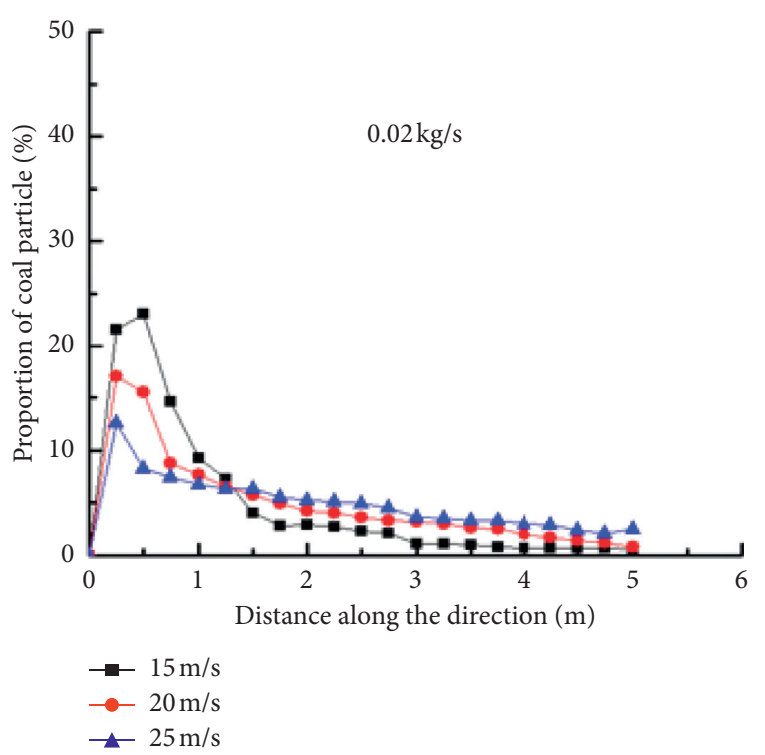

(a)

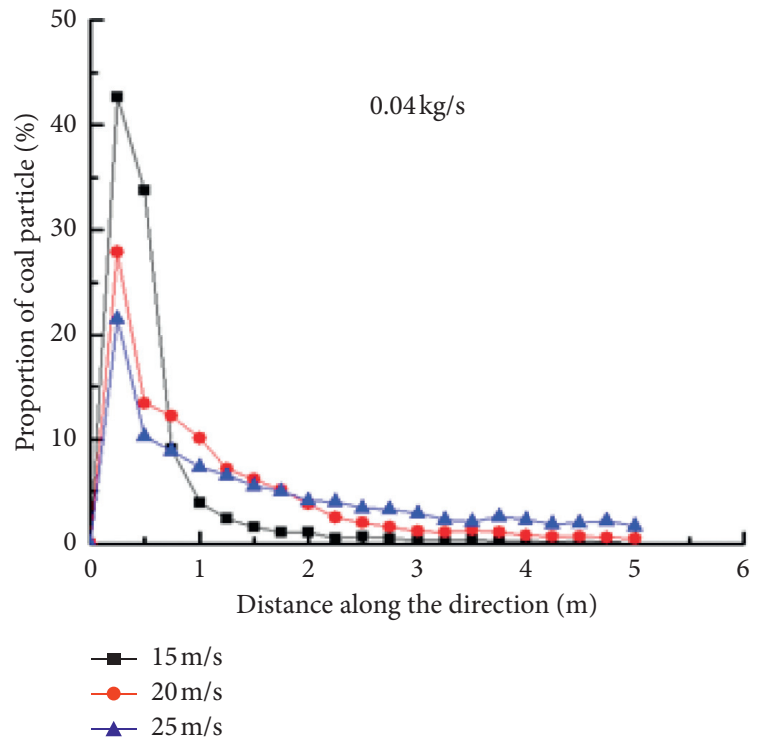

(c)

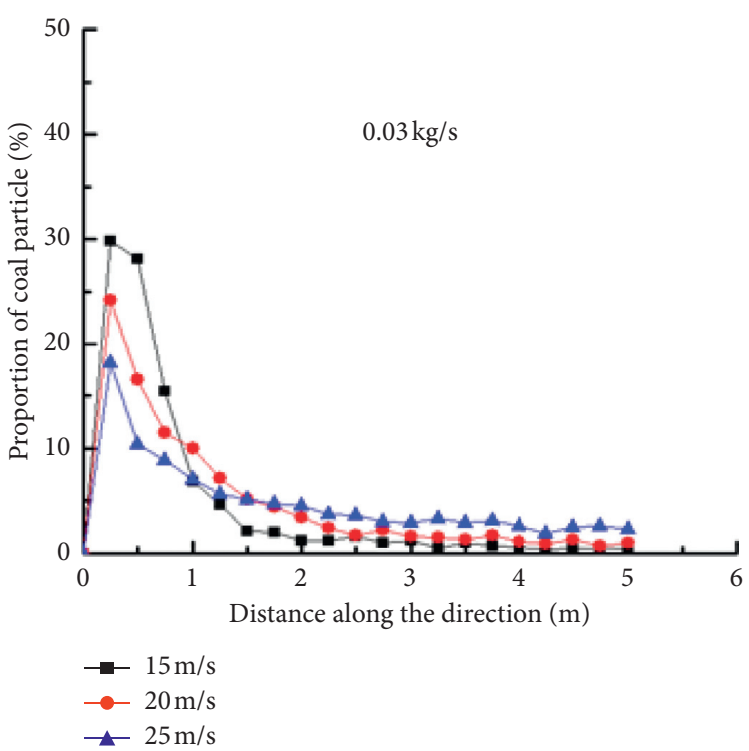

(b)

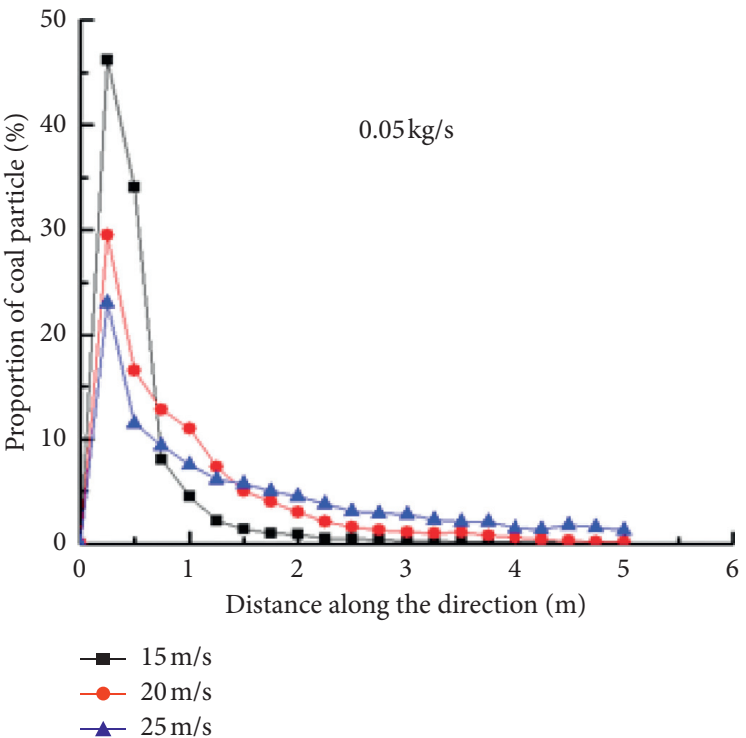

(d)

Figure 11: Particle number distribution along the flow direction.

$0 \mathrm{~m} \sim 0.5 \mathrm{~m}$ section; in the $1-3 \mathrm{~m}$ section, the velocity of most of the coal particles was about $6 \mathrm{~m} / \mathrm{s}$, and a small quantity of the coal particle had a velocity of $7.5 \mathrm{~m} / \mathrm{s}$. In the $3 \sim 5 \mathrm{~m}$ section, the velocity of coal particle was mostly above $6 \mathrm{~m} / \mathrm{s}$, and the highest velocity realized was about $9 \mathrm{~m} / \mathrm{s}$.

When the gas velocity increased to $20 \mathrm{~m} / \mathrm{s}$, only a small quantity of coal particle velocity was within the range of $3 \mathrm{~m} / \mathrm{s}$ in the $0 \mathrm{~m} \sim 0.5 \mathrm{~m}$ section. At the position of $3 \mathrm{~m}$, the coal particles velocity was mostly above $6 \mathrm{~m} / \mathrm{s}$, while at $5 \mathrm{~m}$ the velocity of coal particle increased to $9 \mathrm{~m} / \mathrm{s}$.

When the gas velocity increased to $25 \mathrm{~m} / \mathrm{s}$, the number of coal particles having a velocity of $3 \mathrm{~m} / \mathrm{s}$ reduced further in the $0-0.5 \mathrm{~m}$ section, while in the $0-2 \mathrm{~m}$ section the coal particle accelerated to above $6 \mathrm{~m} / \mathrm{s}$ at about $2.25 \mathrm{~m}$. All the coal particle velocities increased to above $12 \mathrm{~m} / \mathrm{s}$ at $5 \mathrm{~m}$.
Figure 14 shows that when the gas velocity was $15 \mathrm{~m} / \mathrm{s}$, the coal particles velocity was less than $1.6 \mathrm{~m} / \mathrm{s}$ in the $0 \mathrm{~m} \sim 0.5 \mathrm{~m}$ section, while a few particles velocities increased to $6 \mathrm{~m} / \mathrm{s}$; in the $1 \mathrm{~m} \sim 2.75 \mathrm{~m}$ section, most of the coal particles velocity was approximately $3 \mathrm{~m} / \mathrm{s}$, and the velocity of most of the coal particle $s$ was below $6 \mathrm{~m} / \mathrm{s}$ at $5 \mathrm{~m}$.

When the gas velocity increased to $20 \mathrm{~m} / \mathrm{s}$, the coal particle velocity was within the range of $6 \mathrm{~m} / \mathrm{s}$ in the $0 \mathrm{~m} \sim 0.5 \mathrm{~m}$ section. At $2.75 \mathrm{~m}$, the velocity of the coal particles was mostly above $6 \mathrm{~m} / \mathrm{s}$ and their velocity increased to $9 \mathrm{~m} / \mathrm{s}$ at $5 \mathrm{~m}$.

When the gas velocity increased to $25 \mathrm{~m} / \mathrm{s}$, most of the coal particles velocity was within $9 \mathrm{~m} / \mathrm{s}$ in the $0 \mathrm{~m}-0.5 \mathrm{~m}$ section, and their velocity was above $6 \mathrm{~m} / \mathrm{s}$ at about $2.5 \mathrm{~m}$. However, all the coal particle velocities had increased to more than $11 \mathrm{~m} / \mathrm{s}$ at $5 \mathrm{~m}$. 


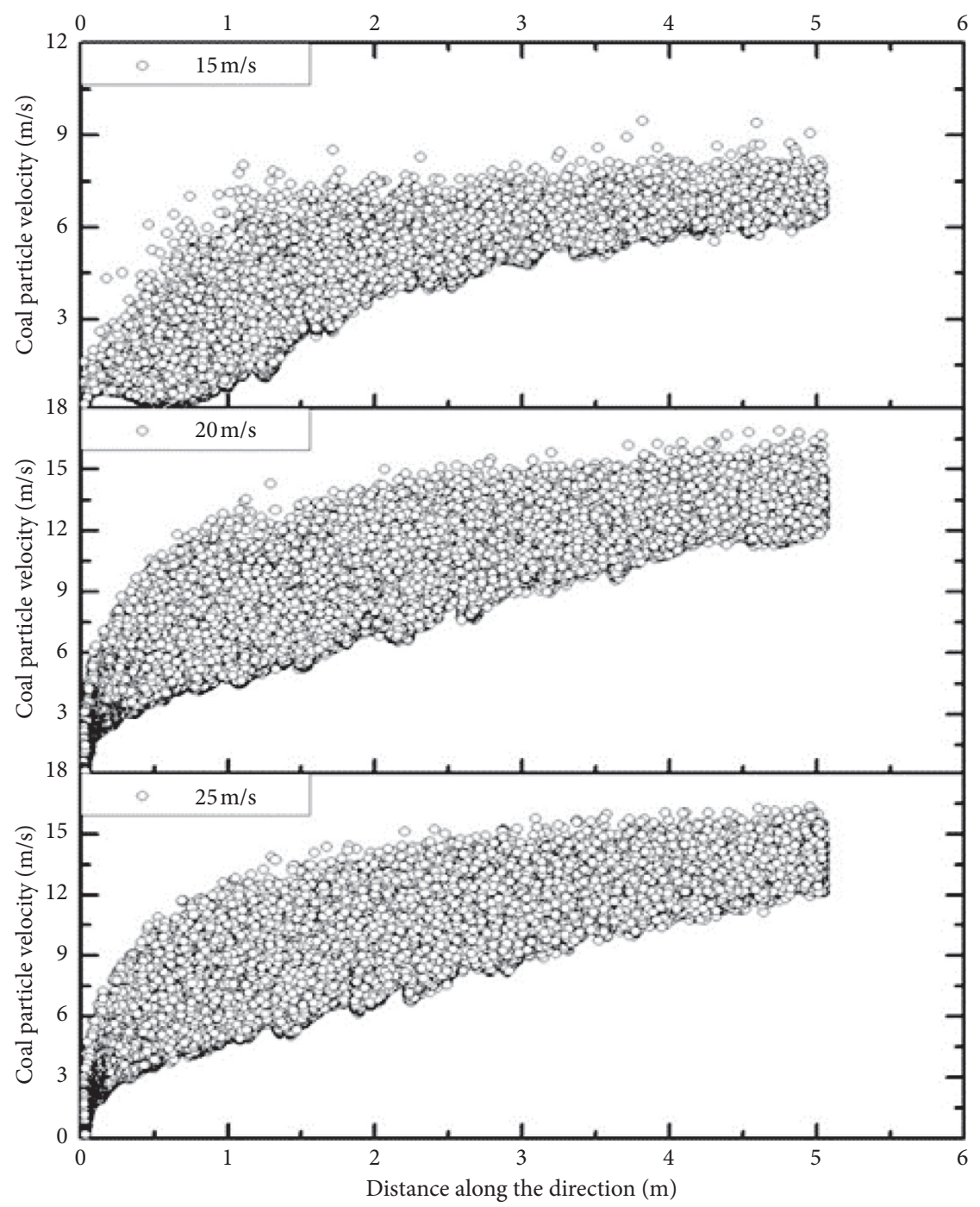

FIGURE 12: Coal particle velocity distribution along the flow direction with particle generation rate of $0.02 \mathrm{~kg} / \mathrm{s}(t=3.0 \mathrm{~s})$.

According to Figure 15, when the gas velocity was $15 \mathrm{~m} /$ $\mathrm{s}$, the coal particle velocity was less than $1.6 \mathrm{~m} / \mathrm{s}$ in the $0 \mathrm{~m} \sim 0.5 \mathrm{~m}$ section, while the velocity of a few particles increased to $6 \mathrm{~m} / \mathrm{s}$; in the $1 \mathrm{~m} \sim 2.75 \mathrm{~m}$ section, most of the coal particles had a velocity of $3 \mathrm{~m} / \mathrm{s}$, and their velocity in this section was mostly below $6 \mathrm{~m} / \mathrm{s}$ at $5 \mathrm{~m}$.

At a gas velocity of $20 \mathrm{~m} / \mathrm{s}$, the coal particle velocity was within the range of $6 \mathrm{~m} / \mathrm{s}$ in the $0 \mathrm{~m} \sim 0.5 \mathrm{~m}$ section. At $2.75 \mathrm{~m}$, the velocity of coal particles was mostly above $6 \mathrm{~m} / \mathrm{s}$ and at $5 \mathrm{~m}$ their velocity increased to $9 \mathrm{~m} / \mathrm{s}$.

When the gas velocity increased to $25 \mathrm{~m} / \mathrm{s}$, most of the coal particle velocity was within $9 \mathrm{~m} / \mathrm{s}$ in the $0 \mathrm{~m}-0.5 \mathrm{~m}$ zone, and $t$ velocity was above $6 \mathrm{~m} / \mathrm{s}$ at $2.5 \mathrm{~m}$. All the coal particle velocities increased to more than $11 \mathrm{~m} / \mathrm{s}$ at $5 \mathrm{~m}$.

4.6.3. Proportion of Coal Particles at Different Locations. Quantitative characterization of the number of coal particles having the same velocity in the $0 \mathrm{~m} \sim 5 \mathrm{~m}$ section of bit-drill rod can quantify the acceleration characteristics of coal particle under different conditions. The ratio of coal particle velocity at different positions was defined as the ratio of coal particle number at a certain velocity at a position to the total number of coal particles in the $0 \mathrm{~m}-5 \mathrm{~m}$ section, as shown in Figure 16.

Figure 16 depicts the fact that when the coal particle mass flow rate was $0.02 \mathrm{~kg} / \mathrm{s}$, the quantity of coal particles with a velocity of $0 \mathrm{~m} / \mathrm{s}$ to $6 \mathrm{~m} / \mathrm{s}$ had about $2.58 \%$ of the total coal particle with a gas velocity of $15 \mathrm{~m} / \mathrm{s}$. When the gas velocity increased to $20 \mathrm{~m} / \mathrm{s}$, the proportion of coal particle with velocity of $0 \mathrm{~m} / \mathrm{s}$ to $6 \mathrm{~m} / \mathrm{s}$ increased to $30.24 \%$, which was equivalent to an increment of $1071.46 \%$. When the gas velocity reached $25 \mathrm{~m} / \mathrm{s}$, the proportion of coal particles with a velocity of $0 \mathrm{~m} / \mathrm{s} \sim 6 \mathrm{~m} / \mathrm{s}$ increased to $58.35 \%$, which was an increment of $92.90 \%$ compared to the gas velocity of $20 \mathrm{~m} / \mathrm{s}$.

When the coal particle mass flow rate was $0.03 \mathrm{~kg} / \mathrm{s}$, $2.16 \%$ of the amount of coal particle with velocity $0 \mathrm{~m} / \mathrm{s}$ to $6 \mathrm{~m} / \mathrm{s}$ had a gas velocity of $15 \mathrm{~m} / \mathrm{s}$. When the gas velocity reached $20 \mathrm{~m} / \mathrm{s}$, the proportion of particle with velocity with $0-6 \mathrm{~m} / \mathrm{s}$ increased to $18.74 \%$, which was an increment of $765.58 \%$. When the gas velocity increased to $25 \mathrm{~m} / \mathrm{s}$, the proportion of coal particle with a velocity of $0 \mathrm{~m} / \mathrm{s} \sim 6 \mathrm{~m} / \mathrm{s}$ 


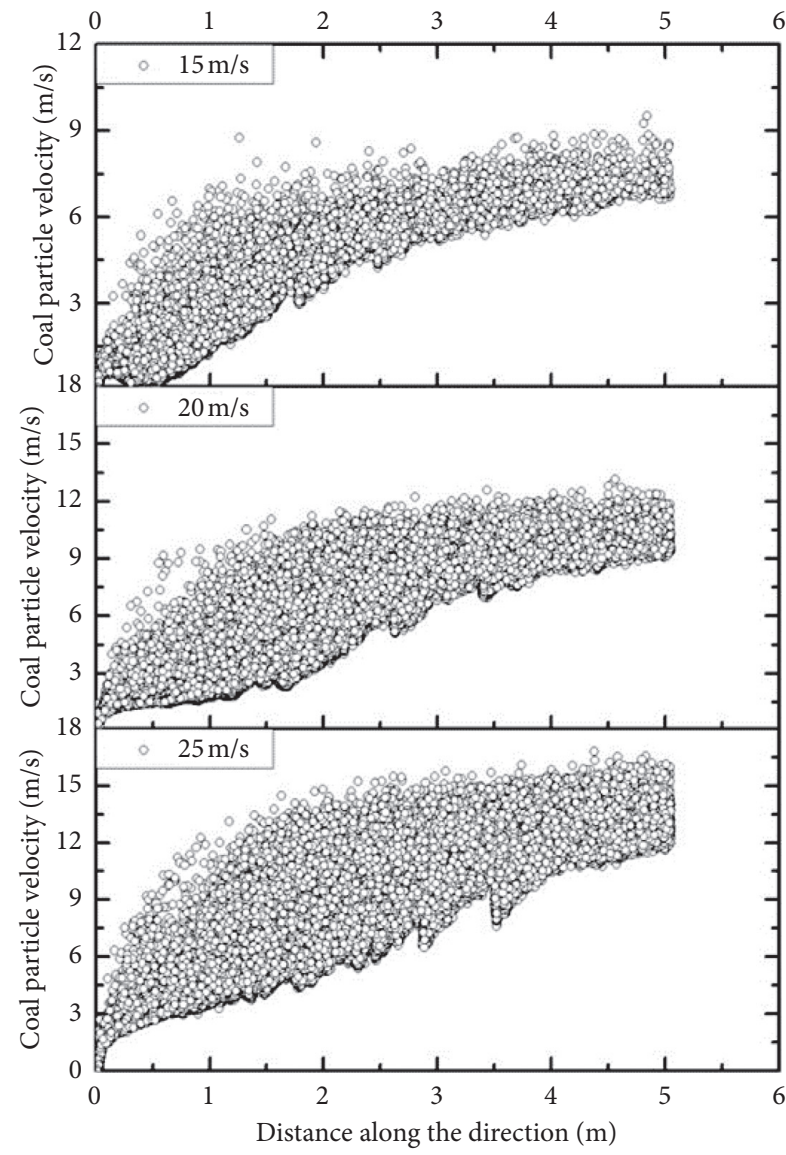

FIGURE 13: Coal particle velocity distribution along the flow direction with particle generation rate of $0.03 \mathrm{~kg} / \mathrm{s}(t=3.0 \mathrm{~s})$.

increased to $43.02 \%$, which was equivalent to an increment of $129.56 \%$ compared to that of gas velocity of $20 \mathrm{~m} / \mathrm{s}$.

When the coal particle mass flow rate was $0.04 \mathrm{~kg} / \mathrm{s}$, of total amount of coal particle with velocity of $0 \mathrm{~m} / \mathrm{s}$ to $6 \mathrm{~m} / \mathrm{s}$, about $1.70 \%$ had a gas velocity of $15 \mathrm{~m} / \mathrm{s}$. When the gas velocity increased to $20 \mathrm{~m} / \mathrm{s}$, the proportion of particle with velocity of $0 \mathrm{~m} / \mathrm{s}$ to $6 \mathrm{~m} / \mathrm{s}$ increased to $15.56 \%$, representing an increment of $813.59 \%$. When the gas velocity reached $25 \mathrm{~m} / \mathrm{s}$, the proportion of coal particle with velocity of $0 \mathrm{~m} /$ $\mathrm{s} \sim 6 \mathrm{~m} / \mathrm{s}$ increased to $36.48 \%$, which was an increment of $134.56 \%$ compared to the gas velocity of $20 \mathrm{~m} / \mathrm{s}$.

When the coal particle mass flow rate was $0.05 \mathrm{~kg} / \mathrm{s}$, the amount of coal particle with a velocity $0 \mathrm{~m} / \mathrm{s}$ to $6 \mathrm{~m} / \mathrm{s} \mathrm{had}$ $0.88 \%$ of the total coal particle gas velocity of $15 \mathrm{~m} / \mathrm{s}$. When the gas velocity reached $20 \mathrm{~m} / \mathrm{s}$, the proportion of particle with velocity of $0 \mathrm{~m} / \mathrm{s}$ to $6 \mathrm{~m} / \mathrm{s}$ had the total coal particle that increased to $10.85 \%$, which was an increase of $1132.96 \%$. When the gas velocity reached $25 \mathrm{~m} / \mathrm{s}$, the proportion of coal particle with $0 \mathrm{~m} / \mathrm{s} \sim 6 \mathrm{~m} / \mathrm{s}$ in the total coal particle increased to $31.89 \%$, which was an increment of $193.88 \%$ compared to the gas velocity of $20 \mathrm{~m} / \mathrm{s}$.

4.6.4. Bottom Flow Length and Acceleration Suspension Distance. The acceleration of coal particle to the suspension velocity under the action of gas was the prerequisite for

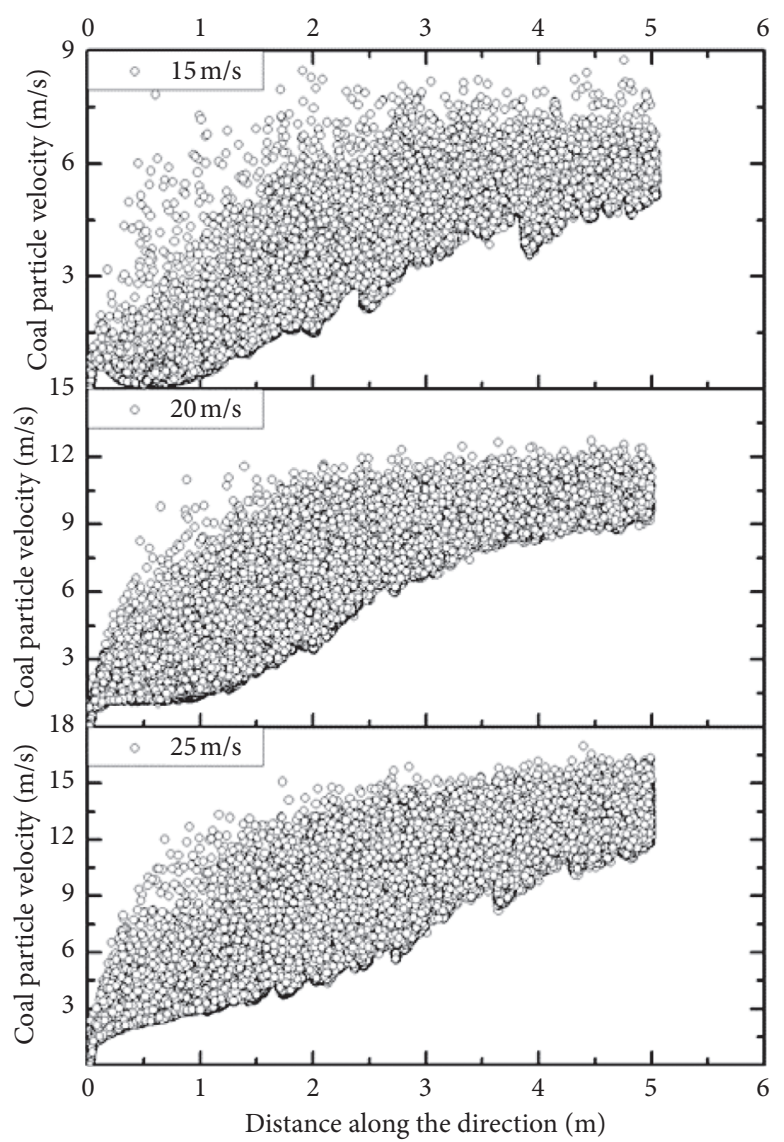

Figure 14: Particle velocity distribution along the flow direction with particle generation rate of $0.04 \mathrm{~kg} / \mathrm{s}(t=3.0 \mathrm{~s})$.

suspension flow. Correspondingly, the coal particle underwent an accelerated motion at the bottom of the drill rod. As the coal particle velocity increased, the bottom flow characteristics disappeared and gradually changed to suspension flow. Bottom flow length, which is the distance from the end of the drill bit when the significant bottom flow characteristic appears as it disappears along the flow direction $(0 \mathrm{~m} \sim 5 \mathrm{~m})$, was defined. Suspension acceleration distance was defined as the coal particle flow distance from where it enters the drill rod to where the particle velocity reaches the suspension velocity under different working conditions. The bottom flow length and suspension acceleration distance under different conditions are as shown in Figures 17(a) and 17(b), respectively.

Figure 17 depicts the fact that the bottom flow length was about $2.25 \mathrm{~m}$ and $4.81 \mathrm{~m}$ when the coal particle mass flow rate was $0.02 \mathrm{~kg} / \mathrm{s}$ and $0.03 \mathrm{~kg} / \mathrm{s}$ with gas velocity $15 \mathrm{~m} / \mathrm{s}$, respectively. When the coal particle mass flow rate increased to $0.04 \mathrm{~kg} / \mathrm{s}$ and $0.05 \mathrm{~kg} / \mathrm{s}$, there was still a significant bottom flow at $5 \mathrm{~m}$. When the gas velocity increased to $20 \mathrm{~m} / \mathrm{s}$, the characteristic of bottom flow reduced significantly, and the bottom flow length was about $1.7 \mathrm{~m}, 2.37 \mathrm{~m}, 3.27 \mathrm{~m}$, and $3.68 \mathrm{~m}$ when the coal particle mass flow rate was $0.02 \mathrm{~kg} / \mathrm{s}$, $0.03 \mathrm{~kg} / \mathrm{s}, 0.04 \mathrm{~kg} / \mathrm{s}$, and $0.05 \mathrm{~kg} / \mathrm{s}$, respectively. When the gas velocity was $25 \mathrm{~m} / \mathrm{s}$, the effect of bottom flow length was little under coal particle flow rate of $0.02 \mathrm{~kg} / \mathrm{s}$ and $0.03 \mathrm{~kg} / \mathrm{s}$ and 


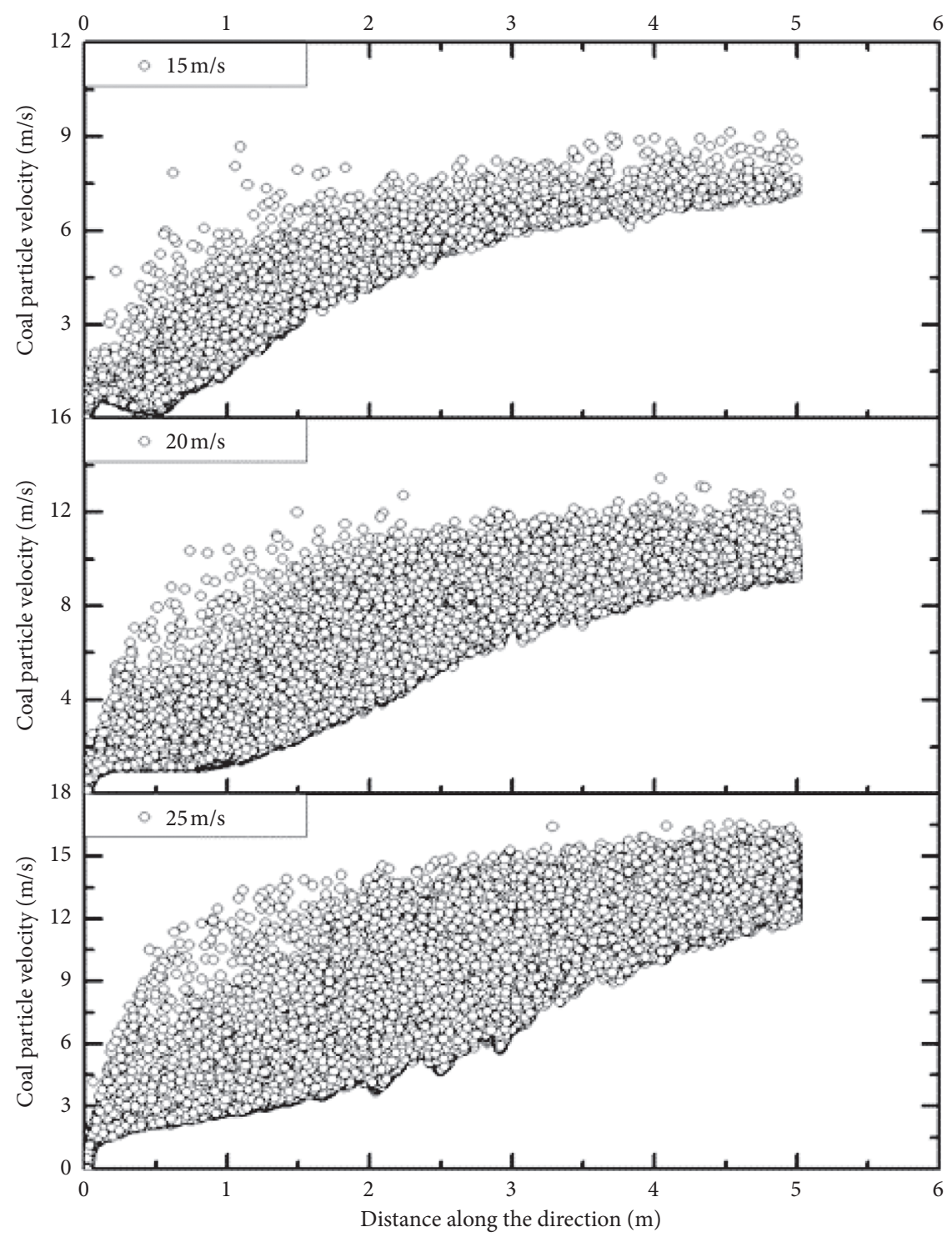

Figure 15: Particle velocity distribution along the flow direction with particle generation rate of $0.05 \mathrm{~kg} / \mathrm{s}(t=3.0 \mathrm{~s})$.

reduced to $1.58 \mathrm{~m}$ and $2.11 \mathrm{~m}$, respectively. Conversely, the bottom flow length under coal particle flow rate $0.04 \mathrm{~kg} / \mathrm{s}$ and $0.05 \mathrm{~kg} / \mathrm{s}$ had greater influence, with reduction to $2.74 \mathrm{~m}$ and $2.85 \mathrm{~m}$, respectively.

The coal particle flowed into the drilling bit and moved along the drill rod bottom because the gas velocity was too low to timely accelerate the coal particles under the gas velocity of $15 \mathrm{~m} / \mathrm{s}$. The coal particle velocity distribution in the $0 \mathrm{~m}-0.5 \mathrm{~m}$ part was within $3 \mathrm{~m} / \mathrm{s}, 2.25 \mathrm{~m} / \mathrm{s}, 1.6 \mathrm{~m} / \mathrm{s}$, and $0.93 \mathrm{~m} / \mathrm{s}$, respectively, which were far less than the suspension velocity of coal particle $(6 \mathrm{~m} / \mathrm{s})$ when the coal particle mass flow rates were $0.02 \mathrm{~kg} / \mathrm{s}, 0.03 \mathrm{~kg} / \mathrm{s}, 0.04 \mathrm{~kg} / \mathrm{s}$, and $0.05 \mathrm{~kg} / \mathrm{s}$, as shown in Figures 5 to 7 , and the proportions of coal particle in this section were $44.67 \%, 57.98 \%, 76.49 \%$, and $80.30 \%$, respectively. The more the quantity of particles, the more the particle-particle interaction, leading to a remarkable agglomeration effect of coal particle [20], thus increasing the particle suspension velocity, particle gravity, and the bottom flow characteristics. Therefore, the bottom flow characteristics of coal particle became more and more pronounced with the coal particle mass flow rate increasing at gas velocity of $15 \mathrm{~m} / \mathrm{s}$.

When the gas velocity reached $25 \mathrm{~m} / \mathrm{s}$, the initial drag force provided by the gas flow to the coal particle increased by $55 \%$ compared with that of gas velocity of $20 \mathrm{~m} / \mathrm{s}$, and the acceleration energy of the coal particle increased. Therefore, the coal particle accelerated faster under lower coal particle mass flow rate, and the proportion of higher coal particle velocity increased, especially the proportion of coal particle velocity higher than the suspension velocity that increased to 


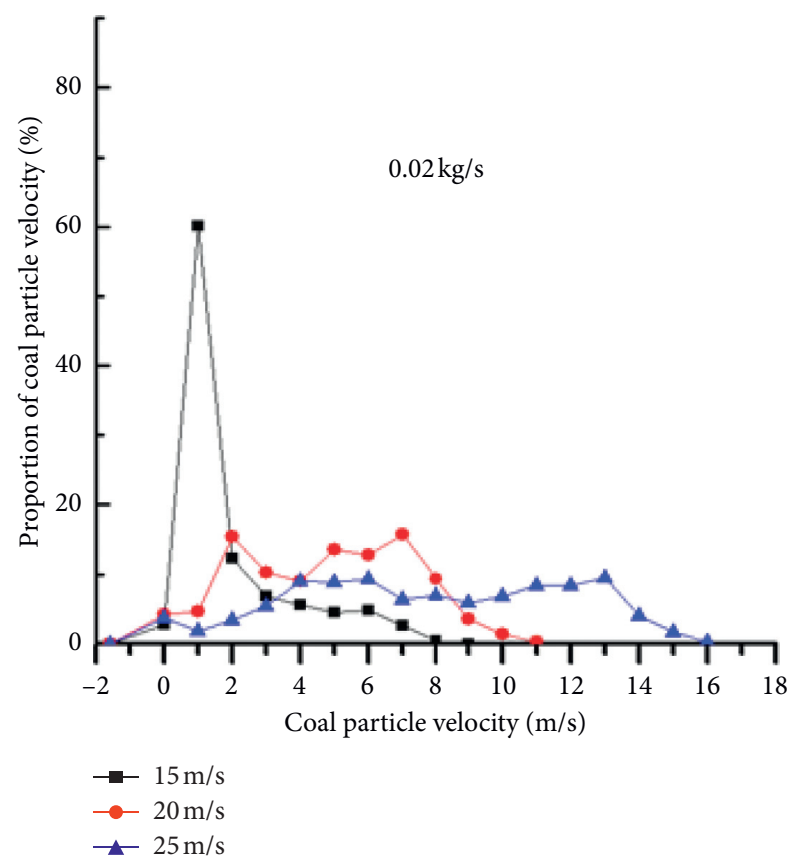

(a)

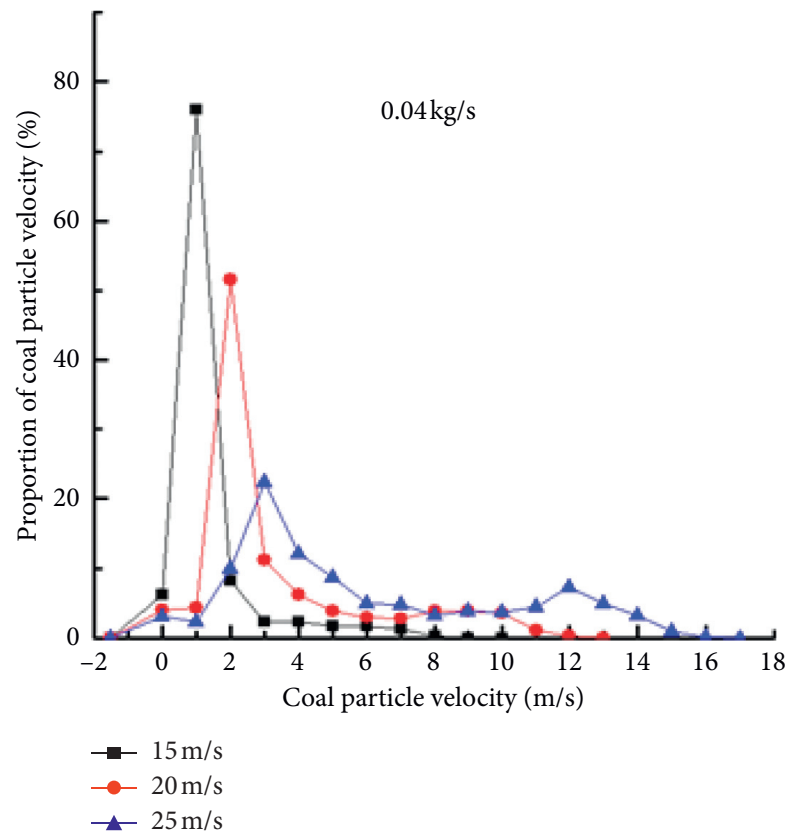

(c)

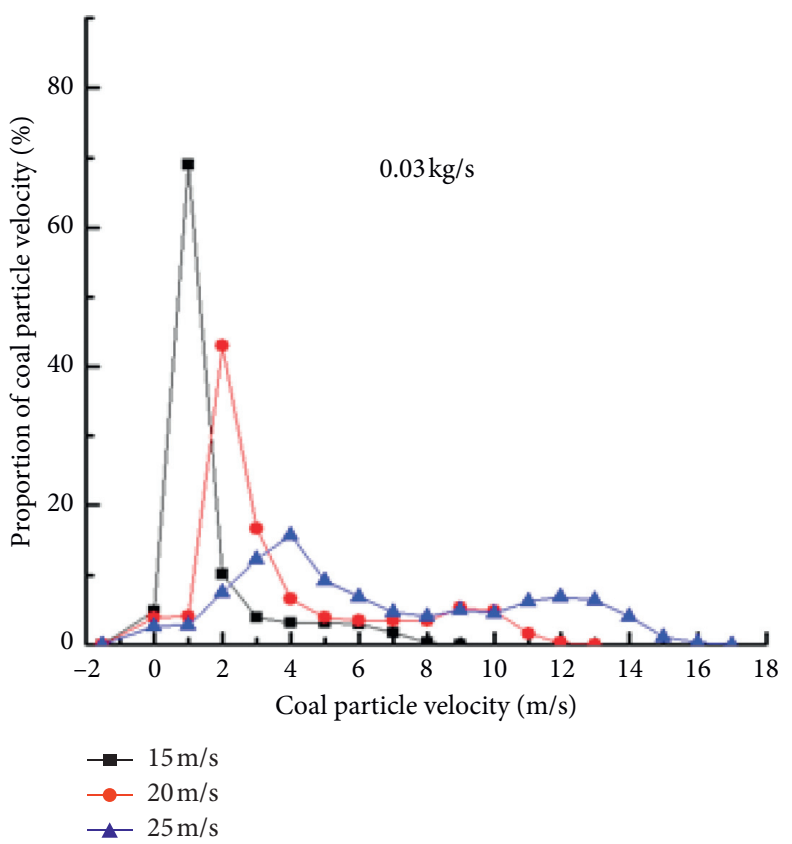

(b)

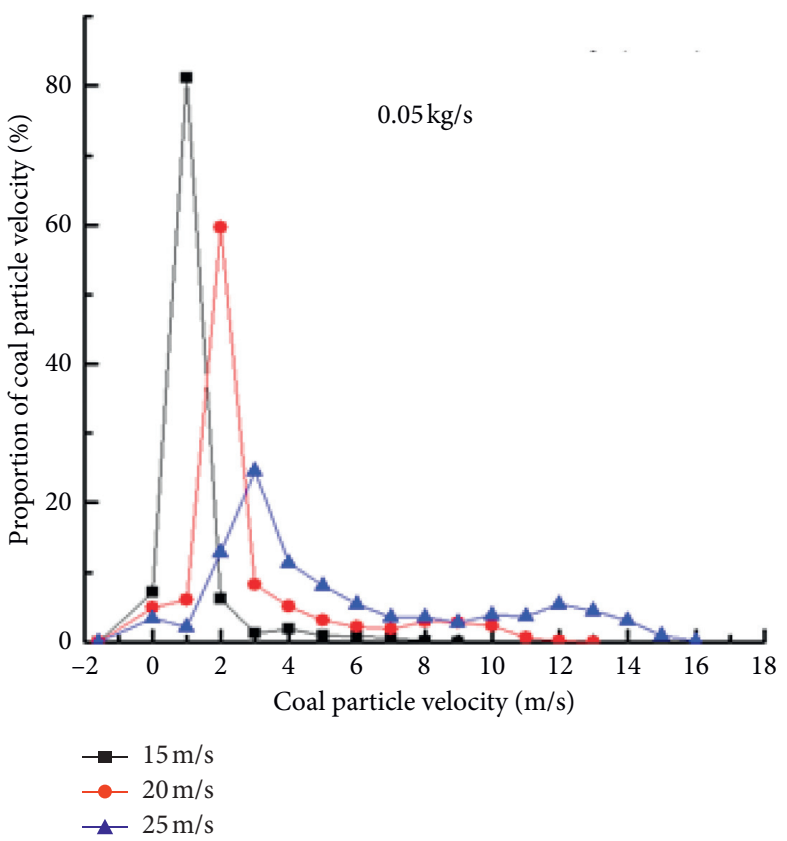

(d)

Figure 16: Percentage of different particle velocities.

$58.35 \%, 43.01 \%, 36.49 \%$, and $31.89 \%$, while the proportion of coal particle fell to $20.92 \%, 28.55 \%, 31.83 \%$, and $24.50 \%$ correspondingly. Therefore, the bottom flow characteristics of coal particle were further weakened compared with $20 \mathrm{~m} / \mathrm{s}$.

It is noteworthy that there was an area of high coal particle thickness in the $0-0.5 \mathrm{~m}$ section of bit-drill rod with obvious bottom flow characteristics. After passing through this area, some of the coal particles quickly changed into a suspension state because an increased coal particle layer thickness was equivalent to a reduction in the flow area of the gas flow, leading to an increase of the gas velocity. At the same time, the drag between the coal particle and gas increased, and the rate of acceleration increased. Secondly, the increase in the airflow velocity, according to Bernoulli equation, increased the static pressure of the lower part of the drill pipe $b$ than that in the upper part. The pressure gradient force promoted the upward movement of coal particles. Suspended coal particle also flowed in the upper part of the drill rod. Therefore, the bottom flow characteristics of coal particle in the drill 


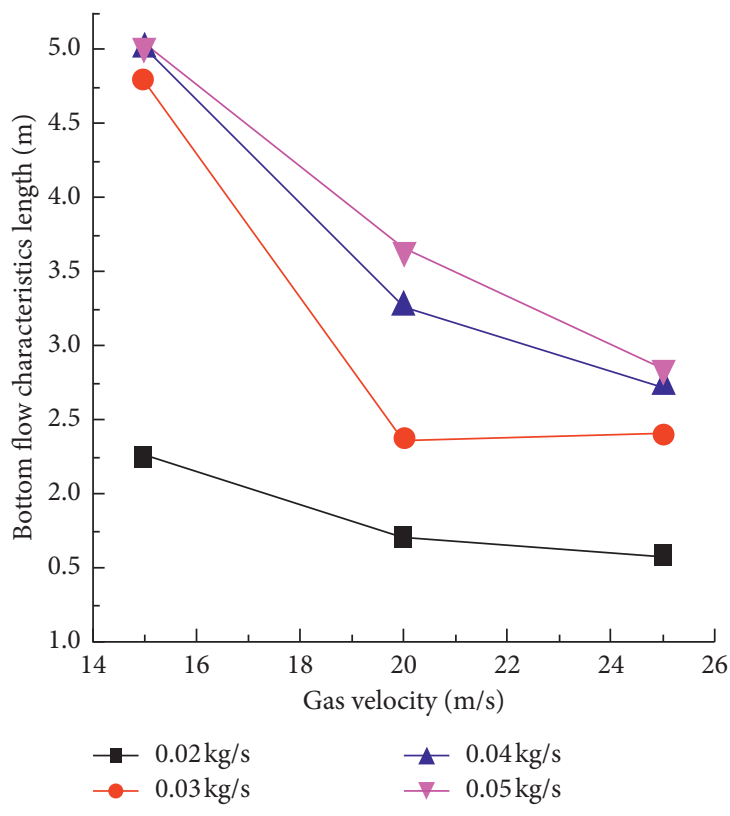

(a)

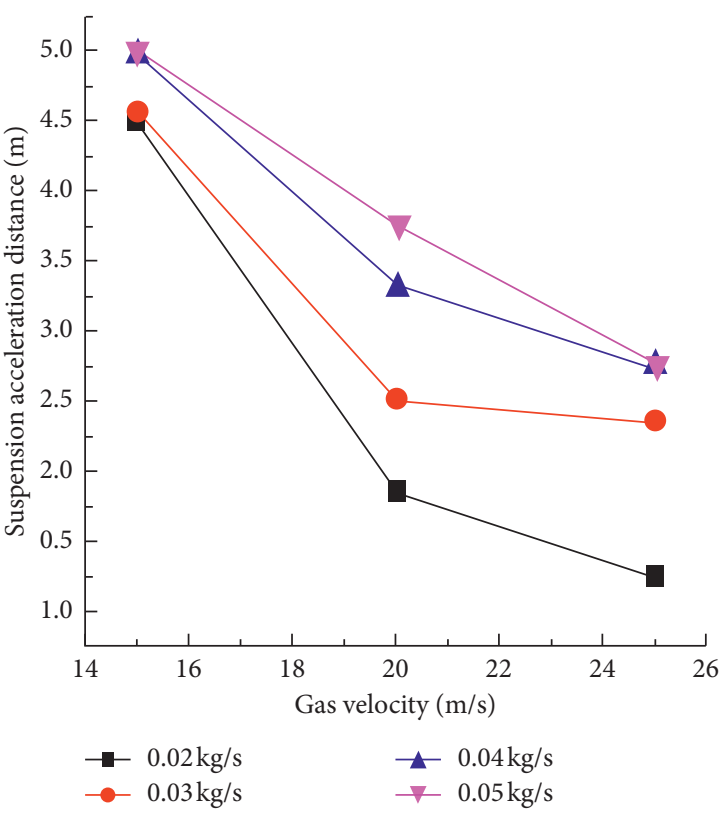

(b)

FIgURE 17: The characteristic length of bottom flow and the suspension acceleration distance.

rod decreased in the $0-0.5 \mathrm{~m}$ section with increasing gas velocity.

\section{Conclusions}

In this work, the CFD-DEM coupled numerical simulation method is applied to the special PDC drill-drill pipe flow structure. The following conclusions are drawn from the results:

(1) For the gas phase, there was a reverse velocity zone at the PDC bit. With increasing gas velocity, the reverse velocity zone gradually shrinked; and there was a high-velocity band in the drill rod. As the gas velocity increased, the high-velocity strip gradually became apparent.

(2) For the particle phase, at the PDC bit, there was an obvious bottom flow characteristic, and there was an area of the highest layer thickness in the drill rod part. At the same gas velocity, the area of the highest thickness layer advanced with the increasing of coal particle mass flow rate.

(3) The velocity of coal particle increased rapidly with the gas velocity, the bottom flow characteristics of coal particle weakened, and the suspension flow gradually appeared.

(4) For the application of sampling method based on negative pressure pneumatic conveying, the values of gas velocity and coal particle mass flow rate should be determined according to the actual engineering conditions for successful sampling.

It is noteworthy that the particle size of coal or rock drilling particle was distributed in $0.25 \sim 3 \mathrm{~mm}$ according to the hardness of the coal or rock formation in engineering practices. However, because the particles number is an important factor affecting the calculation efficiency of the CFD-DEM coupled simulation method and the particle size distribution of coal particles obtained in the field, a fixed particle size of $2 \mathrm{~mm}$ was selected in this study. The gas-solid flow characteristics under different particle size distributions will be paid more attention subsequently.

\section{Data Availability}

The raw/processed data required to reproduce these findings cannot be shared at this time as the data also form part of an ongoing study.

\section{Conflicts of Interest}

The authors declare that they have no conflicts of interest regarding this work.

\section{Acknowledgments}

This work was financially supported by the National Natural Science Foundation of China (no. 51904095), Key Scientific and Technological Projects in Henan Province (no. 192102310200), Higher Education Key Research Projects of Henan Provincial Education Department (no. 18A440003), China Postdoctoral Fund (no. 2020M672229), and the fund of the State Key Laboratory Cultivation Base for Gas Geology and Gas Control (Henan Polytechnic University) (no. WS2019B11).

\section{References}

[1] N. Huber and M. Sommerfeld, "Modelling and numerical calculation of dilute-phase pneumatic conveying in pipe systems," Powder Technology, vol. 99, no. 1, pp. 90-101, 1998. 
[2] S. Laín and M. Sommerfeld, "Numerical calculation of pneumatic conveying in horizontal channels 645 and pipes: detailed analysis of conveying behaviour," International Journal of Multiphase Flow, vol. 39, no. 646, pp. 105-120, 2012.

[3] M. Sommerfeld and S. Lain, "Parameters influencing dilutephase pneumatic conveying through pipe systems: a computational study by the Euler/Lagrange approach," The Canadian Journal of Chemical Engineering, vol. 93, no. 1, pp. 1-17, 2015.

[4] N. A. Patankar and D. D. Joseph, "Modeling and numerical simulation of particulate flows by the Eulerian-Lagrangian approach," International Journal of Multiphase Flow, vol. 27, no. 10, pp. 1659-1684, 2001.

[5] M. Mezhericher, T. Brosh, and A. Levy, "Modeling of particle pneumatic conveying using DEM and DPM methods," Particulate Science and Technology, vol. 29, no. 2, pp. 197-208, 2011.

[6] Y. Tsuji, T. Kawaguchi, and T. Tanaka, "Discrete particle simulation of two-dimensional fluidized bed," Powder Technology, vol. 77, no. 1, pp. 79-87, 1993.

[7] S. Akhshik, M. Behzad, and M. Rajabi, "CFD-DEM simulation of the hole cleaning process in a deviated well drilling: the effects of particle shape," Particuology, vol. 25, pp. 72-82, 2016.

[8] S. Akhshik, M. Behzad, and M. Rajabi, "CFD-DEM approach to investigate the effect of drill pipe rotation on cuttings transport behavior," Journal of Petroleum Science and Engineering, vol. 127, pp. 229-244, 2015.

[9] H. Li, Y. Li, F. Gao, Z. Zhao, and L. Xu, "CFD-DEM simulation of material motion in air-and-screen cleaning device," Computers and Electronics in Agriculture, vol. 88, pp. 111-119, 2012.

[10] F. Dai, X. Song, W. Zhao et al., "Motion simulation and test on threshed grains in tapered threshing and transmission device for plot wheat breeding based on CFD-DEM," International Journal of Agricultural and Biological Engineering, vol. 12, no. 1, pp. 66-73, 2019.

[11] H. Kruggel-Emden and T. Oschmann, "Numerical study of rope formation and dispersion of non-spherical particles during pneumatic conveying in a pipe bend," Powder Technology, vol. 268, pp. 219-236, 2014.

[12] A. Kumar, S. Gupta, K. Pal, and D. R. Kaushal, "CFD modeling for pressure drop in pneumatic conveying through pipe bend," International Journal of Advances in Engineering Sciences, vol. 4, no. 3, pp. 16-19, 2014.

[13] M. W. Korevaar, J. T. Padding, M. A. Van Der Hoef, and J. A. M. Kuipers, "Integrated DEM-CFD modeling of the contact charging of pneumatically conveyed powders," Powder Technology, vol. 258, pp. 144-156, 2014.

[14] I. Lecreps, O. Orozovic, T. Erden, M. G. Jones, and K. Sommer, "Physical mechanisms involved in slug transport and pipe blockage during horizontal pneumatic conveying," Powder Technology, vol. 262, pp. 82-95, 2014.

[15] B. Shao, Y. Yan, X. Yan, and Z. Xu, "A study on non-spherical cuttings transport in CBM well drilling by coupled CFDDEM," Engineering Applications of Computational Fluid Mechanics, vol. 13, no. 1, pp. 579-590, 2019.

[16] F. Zhou, S. Hu, Y. Liu, C. Liu, and T. Xia, "CFD-DEM simulation of the pneumatic conveying of fine particles through a horizontal slit," Particuology, vol. 16, pp. 196-205, 2014.

[17] J. Wei, H. Zhang, Y. Wang, Z. Wen, B. Yao, and J. Dong, "The gas-solid flow characteristics of cyclones," Powder Technology, vol. 308, pp. 178-192, 2017.
[18] A. Di Renzo and F. P. Di Maio, "Comparison of contact-force models for the simulation of collisions in DEM-based granular flow codes," Chemical Engineering Science, vol. 59, no. 3, pp. 525-541, 2004.

[19] G. A. Bokkers, M. Van Sint Annaland, and J. A. M. Kuipers, "Mixing and segregation in a bidisperse gas-solid fluidised bed: a numerical and experimental study," Powder Technology, vol. 140, no. 3, pp. 176-186, 2004.

[20] R. Naveh, N. M. Tripathi, and H. Kalman, "Experimental pressure drop analysis for horizontal dilute phase particlefluid flows," Powder Technology, vol. 321, pp. 355-368, 2017. 